\title{
One year of continuous measurements constraining methane emissions from the Baltic Sea to the atmosphere using a ship of opportunity
}

\author{
W. Gülzow ${ }^{1}$, G. Rehder ${ }^{1}$, J. Schneider v. Deimling ${ }^{3}$, T. Seifert ${ }^{1}$, and Z. Tóth ${ }^{2}$ \\ ${ }^{1}$ Leibniz Institute for Baltic Sea Research Warnemünde, Seestraße 15, \\ 18119 Rostock, Germany \\ ${ }^{2}$ University of Bremen, Klagenfurter Straße , 28359 Bremen, Germany \\ ${ }^{3}$ Helmholtz Centre for Ocean Research (GEOMAR), Wischhofstr. 1-3, 24148 Kiel, Germany \\ Correspondence to: W. Gülzow (wanda.guelzow@io-warnemuende.de)
}

Received: 24 May 2012 - Published in Biogeosciences Discuss.: 1 August 2012

Revised: 8 November 2012 - Accepted: 23 November 2012 - Published: 8 January 2013

\begin{abstract}
Methane and carbon dioxide were measured with an autonomous and continuous running system on a ferry line crossing the Baltic Sea on a 2-3 day interval from the Mecklenburg Bight to the Gulf of Finland in 2010. Surface methane saturations show great seasonal differences in shallow regions like the Mecklenburg Bight (103-507\%) compared to deeper regions like the Gotland Basin (96-161\%). The influence of controlling parameters like temperature, wind, mixing depth and processes like upwelling, mixing of the water column and sedimentary methane emissions on methane oversaturation and emission to the atmosphere are investigated. Upwelling was found to influence methane surface concentrations in the area of Gotland significantly during the summer period. In February 2010, an event of elevated methane concentrations in the surface water and water column of the Arkona Basin was observed, which could be linked to a wind-derived water level change as a potential triggering mechanism. The Baltic Sea is a source of methane to the atmosphere throughout the year, with highest fluxes occurring during the winter season. Stratification was found to promote the formation of a methane reservoir in deeper regions like Gulf of Finland or Bornholm Basin, which leads to long lasting elevated methane concentrations and enhanced methane fluxes, when mixed to the surface during mixed layer deepening in autumn and winter. Methane concentrations and fluxes from shallow regions like the Mecklenburg Bight are predominantly controlled by sedimentary production and consumption of methane, wind events and the
\end{abstract}

change in temperature-dependent solubility of methane in the surface water. Methane fluxes vary significantly in shallow regions (e.g. Mecklenburg Bight) and regions with a temporal stratification (e.g. Bornholm Basin, Gulf of Finland). On the contrary, areas with a permanent stratification like the Gotland Basin show only small seasonal fluctuations in methane fluxes.

\section{Introduction}

To constrain the biogeochemical cycle of the greenhouse gas methane $\left(\mathrm{CH}_{4}\right)$ and to estimate its future role in climate on earth, processes which influence the strength of its various sources and sinks need to be determined accurately. Numerous studies over the last decades have investigated various methane sources with the aim to quantify their contributions to the global methane budget. Emission estimates of the world's ocean range from $2 \%$ (Bange et al., 1994) to $10 \%$ (Grunwald et al., 2009) of the total global methane source strength to the atmosphere. Significantly smaller emission estimates were calculated for open ocean areas like the $\mathrm{Pa}$ cific Ocean by Bates et al. (1996) with less than $0.1 \%$ of the atmospheric source strength, and the authors point out the underestimation of coastal zones. Bange et al. $(1994,2006)$ also comment the underestimation of shallow marine areas due to the lack of data and the uncertainty of the role of estuaries, shelf and coastal areas, which may contribute $75 \%$ of the 
total marine methane emissions to the atmosphere. In fact, many studies face the limitations of discrete data measurements to adequately observe methane production parameters or investigate processes. Therefore, the marine methane budget and estimations of the resulting fluxes to the atmosphere still contain large uncertainties.

\subsection{Baltic Sea as shallow marginal sea}

The Baltic Sea is located in the northern part of Europe and forms one of the largest brackish water reservoirs on earth with an average water depth of $52 \mathrm{~m}$. Today, the Skagerrak and the Kattegat remain the only connection with the North Sea and the open ocean. A series of submarine sills divide the Baltic Sea into several sub-basins, which can be distinguished and characterized by different geochemical and hydrographical gradients. The positive freshwater balance and episodic saline inflow events from the North Sea lead to the formation of a less saline surface layer and a more saline deep and bottom water layer separated by a halocline. The surface salinity gradient decreases from 17 in the west (Belt Sea) to 3 in the northeast (Bothnian Bay). The vertical salinity gradient is leading to a strong density stratification, hampering vertical mixing. Especially in the central deep regions of the Baltic Sea this stratification persists throughout the year. The limited ventilation together with high productivity leads to the development of a permanent redoxcline, marking the transition from oxic to sub- or anoxic conditions in the deeper stratified basins.

A comprehensive description of climate and weather in the Baltic Sea region has been provided by Feistel et al. (2008).

\subsection{Methane in the Baltic Sea}

Glacial and postglacial sedimentary deposits of the Baltic Sea are characterized by fine-grained, organic rich clay and mud layers (Holocene sediments; Thießen et al., 2006; Laier et al., 2007; Feistel et al., 2008). Methanogenesis of the organic matter in the organic-rich surface sediments is the major methane source in the Baltic Sea (Whiticar and Faber, 1986; Butler et al., 1989; Thießen et al., 2006). This process leads to the occurrence of shallow gas in the sediment, especially in the Arkona and Bornholm Basin (BB; Thießen et al., 2006; Laier and Jensen, 2007). Methane concentrations in anoxic surface sediments are not only controlled by the production but also by the degradation of methane via bacterial oxidation (Boetius et al., 2000; Thießen et al., 2006), whereby $87-99 \%$ of the produced methane is estimated to be oxidized within the sediment (Berger and Heyer, 1990). Pockmark structures and seep areas are potential sources for methane emissions towards the water column, but only few locations are known in the Baltic Sea (Dando et al., 1994; Bussmann and Suess, 1998; Thießen et al., 2006; Pimenov et al., 2010). Additional methane sources which might affect sea surface methane concen- trations are riverine input, groundwater discharge, and formation in the upper water column, including production in anaerobic microniches like digestive tracts of zooplankton (DeAngelis and Lee, 1994), fecal pellets and sinking organic particles (Karl and Tilbrook, 1994) or the use of methylated compounds under oxic conditions (Karl et al., 2008).

Methane generated in the sediment transfers into the water column via diffusion, fluid flow or bubble transport. As a consequence, a methane gradient towards the water surface is usually observed in the Baltic, with high concentrations in the deeper layers and low concentrations at the sea surface (Schmale et al., 2010). During the transport through the water column towards the sea surface, methane is substantially reduced by methane oxidation especially in the oxic/anoxic transition layer, as has been shown for the Black Sea (Schmale et al., 2011). Besides oxidation, methane emission to the atmosphere constitutes another major sink of methane in the Baltic Sea.

There are only few assessments of methane concentrations and fluxes to the atmosphere from the Baltic Sea. Bange et al. (1994) determined atmospheric and dissolved methane using an automated gas chromatographic system and described the Southern Belt Sea and the central Baltic Sea as source for atmospheric methane. Bange and coworkers showed strong seasonal variations in surface methane saturations with high values during the summer (e.g. $168 \%$ Arkona Sea, $157 \%$ Bornholm Sea) and lower values during the winter (e.g. $117 \%$ Arkona Sea, $107 \%$ Bornholm Sea). They highlighted the importance of shallow shelf regions for global methane flux estimations. Bange et al. (1998) described the seasonal distribution of methane and nitrous oxide in the Bodden Sea, using an equilibrator combined with a gas chromatograph, postulating that methane emissions from this area account for $17 \%$ of the total Baltic Sea methane emissions. Monthly observations of the water column at Boknis Eck between 2006 and 2008 showed a bimodal seasonality of sedimentary release of methane and elevated methane concentrations in deep water layers after sedimentation of fresh organic material from phytoplankton blooms (Bange et al., 2010). Similar periodic changes of methane fluxes from the sediment into deeper water layers were observed in the coastal zone of Puck Bay along the Hel Peninsula (Reindl and Bolalek, 2012). Abril and Iversen (2002) described methane emissions to the atmosphere along the salinity gradient in the estuarine zone of Randers Fjord (Denmark) from February to December 2000. They observed that the shallow estuarine morphology increases the influence of the sediment on methane dynamics (production and consumption of methane) compared to deeper regions and amplifies rapid changes in methane concentrations and fluxes due to short and episodic weather events (stormy winds).

In this paper we present the results of the first year of almost intervention-free operation of a system allowing continuous measurements of sea surface methane using a 
continuous equilibration technique in combination with integrated off axis cavity output spectroscopy in the southern and central parts of the Baltic Sea (Gülzow et al., 2011). The system successfully recorded methane and carbon dioxide in surface waters of the Baltic Sea since its installation in November 2009 on the cargo ship Finnmaid. The ferry line connects Travemünde (Germany), Helsinki (Finland) and Gdynia (Poland) and crosses the central Baltic Sea every 2 to 3 days (Fig. 1). The high spatiotemporal data coverage provided by the instrument allows new insights into the seasonal and spatial distribution of methane in the surface water of the Baltic Sea and the governing controls. Selected key areas have been taken for detailed studies of the controlling processes and parameters, including upwelling, stratification and mixing, wind events and water level changes, the seasonal temperature cycle, and the distribution of sedimentary sources.

\section{Methods}

\subsection{Analytical setup on the cargo ship Finnmaid}

In cooperation with the Finnish Institute of Marine Research (SYKE, ALGALINE Project), the Leibniz Institute for Baltic Sea Research Warnemünde (IOW) installed a fully automated measuring and sampling system on the cargo ship Finnmaid, which commutes regularly between Travemünde (Germany), Helsinki (Finland) and Gdynia (Poland) since 1993. The ALGALINE equipment on Finnmaid consists of a fluorometer for continuous recording of the chlorophyll $a$ fluorescence and a sampling system for the laboratory analysis of inorganic nutrients, dissolved and particulate organic matter, and plankton species composition. Sea surface salinity (accuracy 0.001 ) and temperature (accuracy $0.001{ }^{\circ} \mathrm{C}$ ) are recorded using a SeaBird 38 thermosalinograph. The IOW installed a fully automated system for the measurement of surface $\mathrm{CO}_{2}$ partial pressure in 2003 (Schneider et al., 2006), later extended by optode-based recording of surface oxygen (Schneider et al., 2006). An independent continuous measuring system for methane and carbon dioxide was added in 2009 (Gülzow et al., 2011). The current trace gas measuring system consists of two independent established equilibrators joint with a methane/carbon dioxide analyzer (MCA; Los Gatos Research) and a LICOR gas analyzer, respectively. Details about the analytical set up, equilibration theory, essential calculations as well as temperature correction are given in Körtzinger et al. (1996) and Gülzow et al. (2011). Methane and carbon dioxide were determined with a total uncertainty of $<0.8 \%$ (Thomas, 2011). The response times of the system for methane and carbon dioxide were determined with $\tau=676 \mathrm{~s}$ and $\tau=226 \mathrm{~s}$, respectively (Gülzow et al., 2011). The time constant for methane implies that equilibrium between the gaseous and the water phase is reached after $35 \mathrm{~min}(3 \sigma)$. Hence, with
Table 1. For detailed contemplations of regional differences special key areas were selected to merge methane data (saturation values) with mixing depth or meteorological forcing data derived from the regional forecast model COSMO/EU. The subdivision of the area WoG and GoF reflects a better description of the field of interest than one large box, respectively, and improves the technical approach during modeling.

\begin{tabular}{lcc}
\hline Selected area & Latitude $^{\circ} \mathrm{N}$ & Longitude $^{\circ} \mathrm{E}$ \\
\hline Mecklenburg Bight (MB) & $11.62-12.42$ & $54.25-54.65$ \\
Arkona Basin (AB) & $13.25-14.05$ & $54.63-55.03$ \\
Bornholm Basin (BB) & $14.55-15.35$ & $55.29-55.69$ \\
West of Gotland (WoG) with & & \\
West of Gotland 1 & $17.94-18.16$ & $57.58-57.69$ \\
West of Gotland 2 & $18.11-18.34$ & $57.70-57.82$ \\
West of Gotland 3 & $18.29-18.51$ & $57.82-57.94$ \\
East of Gotland (EoG) & $18.50-18.59$ & $51.11-56.87$ \\
Gotland Central Basin (GB) & $19.55-20.35$ & $55.74-56.74$ \\
Gulf of Finland (GoF) with & & \\
Gulf of Finland 1 & $22.65-24.05$ & $59.35-59.67$ \\
Gulf of Finland 2 & $21.95-23.35$ & $59.19-59.51$ \\
Gulf of Finland 3 & $23.35-24.75$ & $59.51-59.83$ \\
\hline
\end{tabular}

the average ship speed of $22 \mathrm{knots}$, the resulting methane signal is smoothed and slightly retarded in time (Gülzow et al., 2011).

\subsection{Sea surface equilibrium calculations}

The atmospheric methane fraction $x_{\mathrm{CH}_{4} \text { atm }}$ [ppm] of the NOAA station BAL (Baltic Sea, Poland, $55.35^{\circ} \mathrm{N} 17.22^{\circ} \mathrm{E}$ ) were used to calculate sea surface equilibrium concentrations. The station is situated 65 nautical miles offshore. Atmospheric samples are taken using a surface flask sampler positioned at $3 \mathrm{~m}$ above sea level. The air samples are collected weekly and analyzed according to the standard evaluation protocol of NOAA (http://www.esrl.noaa.gov/gmd/ ccgg/; Dlugokencky et al., 2011).

The equilibrium concentration $C_{\mathrm{CH}_{4} \mathrm{eq}}[\mathrm{nM}]$ describes the methane concentration in water at a certain salinity and temperature, which is in equilibrium with the overlaying gaseous phase (atmosphere) and can be calculated using the Bunsen coefficient $\beta$ after Wiesenburg and Guinasso (1979).

$C_{\mathrm{CH}_{4} \mathrm{eq}}=\beta \cdot x_{\mathrm{CH}_{4} \mathrm{~atm}}$

The ratio of equilibrium concentration $C_{\mathrm{CH}_{4} \text { eq }}$ and measured seawater concentration $C_{\mathrm{CH}_{4} \text { aq }}[\mathrm{nM}]$ describes the saturation state indicating undersaturation for values below $100 \%$ and oversaturation for values above $100 \%$. The difference of $C_{\mathrm{CH}_{4} \text { eq }}$ and $C_{\mathrm{CH}_{4} \text { aq }}$ is a key parameter for the calculation of sea-air methane fluxes (see Sect. 3.5). 


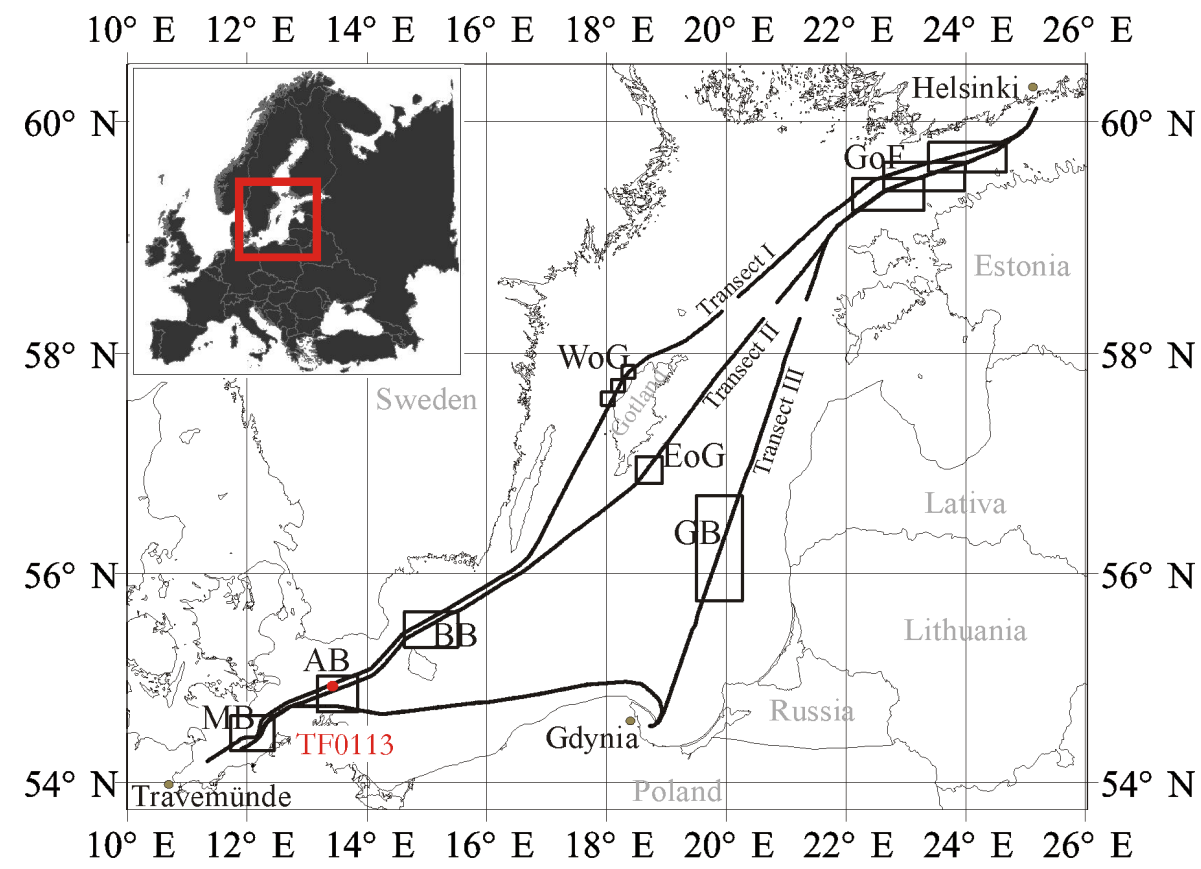

Fig. 1. Cruise tracks of the ship of opportunity Finnmaid. The ferry line crosses the Baltic Sea via three transects and connects Travemünde (Germany) with Helsinki (Finland) and Gdynia (Poland) in an interval of 2 to 3 days. Transect I passes the Mecklenburg Bight (MB), Arkona Basin (AB), Bornholm Basin (BB), West of Gotland (WoG) and the Gulf of Finland (GoF). Transect II records the same route but East of Gotland (EoG). Transect III passes Gdynia and the Gotland Basin (GB). Boxes indicate selected areas for detailed investigations (see also Table 1). Station TF0113 is part of a regular monitoring program of the Leibniz Institute for Baltic Sea Research Warnemünde.

\subsection{Meteorological data}

To estimate the role of wind forcing on sea-air gas exchange in the selected key regions (Table 1) of the Baltic Sea, meteorological forcing data derived from the regional weather forecast model COSMO/EU (former DWD/LME) run by the German Weather Service (DWD) were used (Schulz and Schättler, 2005; COSMO, 2012). The core documentation of the COSMO model is available on the web site of the international Consortium of Small-scale Modeling (COSMO). The non-hydrostatic, high-resolution model COSMO/EU covers the whole of Europe with a bottom grid spacing of $7 \mathrm{~km}$, resolving even small scale spatial changes. The daily variation of meteorological conditions is adequately represented by prescribing a weather forecast every $3 \mathrm{~h}$ and linear interpolation onto the ocean model time steps of $600 \mathrm{~s}$. The coupling atmosphere-ocean fluxes are evaluated in the circulation model MOM-4 according to Beljaars et al. (1994). Point comparisons with observations from two open sea measurement sites at Darß Sill $\left(12.70^{\circ} \mathrm{E}, 54.40^{\circ} \mathrm{N}\right)$ and in Arkona Basin $\left(\mathrm{AB}, 13.85^{\circ} \mathrm{E}, 54.88^{\circ} \mathrm{N}\right)$ reveal that the reliability of $\mathrm{COSMO} / \mathrm{EU}$ forecasts of air pressure, air temperature, wind speed, wind direction, and relative humidity is of the same degree of accordance as shown by Leuenberger et al. (2010) for ensemble forecasts in view of assimilation, e.g. bias in wind speed is well below $-1 \mathrm{~m} \mathrm{~s}^{-1}$, root mean square deviation is around $1.5 \mathrm{~m} \mathrm{~s}^{-1}$, and linear correlation exceeds $90 \%$
(Seifert, 2010). The model derived wind fields were used to derive gas exchange velocities based on the quadratic relation by Wanninkhof (2009).

\subsection{Mixing depth}

The COSMO/EU forecasts were used as input parameters to drive the numerical Baltic Sea model which is based on the Modular Ocean Model (MOM4, Griffies et al., 2004). The model domain comprises the entire Baltic Sea with the western boundary at Skagerrak (at $8.25^{\circ} \mathrm{E}$ ). The sea level at the open boundary and the river runoff to the Baltic Sea are prescribed from data provided by the Swedish Meteorological and Hydrological Institute (SMHI). Temperature and salinity at the open boundary are nudged to monthly mean profiles derived from climatology (Janssen et al., 1999). The model was started from rest with initial conditions taken from a coarser model simulation, which was corrected with measurements. The model was run for the period September 2002 to December 2010. The model bathymetry is based on a one nautical mile grid (Seifert et al., 2001). The upper water column down to $30 \mathrm{~m}$ depth is divided into layers of $1.5 \mathrm{~m}$ thickness to resolve the shallow channels and sills in the southwestern Baltic. The layer thickness gradually increases to $5 \mathrm{~m}$ at a maximum depth of $268 \mathrm{~m}$, corresponding to the deep basins in the central and northern Baltic. This vertical resolution allows the modeling of the local stratification 
and its evolution throughout the year in each of the respective working areas. Sub-grid scale mixing processes are modeled by the MOM-4 adaptation of the scheme (Smagorinski et al., 1963). The development of vertical stratification is simulated by the kpp scheme (Large et al., 1994). Based on the analysis of the stability within the upper water column, fluxes from the sea surface are non-locally distributed to the depth which is mixed by the entrained energy. The mixing depth describes the range of active turbulence in the upper water column. The mixed layer depth is characterized by homogeneous salinity and temperature profiles. Only stronger mixing events are able to diminish the stratification at the bottom of the mixed layer.

\subsection{Sea-air methane flux calculations}

The flux of methane across the sea-air interface $F$ $\left[\mathrm{nmol} \mathrm{m}{ }^{-2} \mathrm{~s}^{-1}\right]$ can be expressed by the concentration difference of methane between the sea surface water $C_{\mathrm{CH}_{4} \text { aq }}$ and the equilibrium concentration with the atmosphere $C_{\mathrm{CH}_{4} \mathrm{eq}}$ (Eq. 1) and the gas transfer velocity $k\left[\mathrm{~cm} \mathrm{~h}^{-1}\right]$.

$F_{\mathrm{CH}_{4}}=k \cdot\left(C_{\mathrm{CH}_{4} \mathrm{aq}}-C_{\mathrm{CH}_{4} \mathrm{eq}}\right)$

The transfer velocity $k$ was calculated using the quadratic relation of Wanninkhof et al. (2009):

$k=0.24 \cdot u^{2} \cdot\left(\left(S c_{\mathrm{sal}} / 660\right)^{-0.5}\right)$

with wind speed $u\left[\mathrm{~m} \mathrm{~s}^{-1}\right]$ in $10 \mathrm{~m}$ height as main driving kinetic parameter and the Schmidt number $S c_{\text {sal }}$ interpolated according to the measured salinity

$S c_{\mathrm{sal}}=\left[\left(S c_{35}-S c_{0}\right) \cdot S a \mathrm{l} / 35\right]+S c_{0}$,

with Schmidt number $S c_{35}$ for saline water (35 psu), Schmidt number $S c_{0}$ for fresh water (0 psu) after Jähne et al. (1987), and measured salinity Sal [psu].

The parameterization of the transfer velocity $k$ as function of the wind speed $u$ is based on a conceptual model for sea-air gas transfer by relating one gas (e.g. ${ }^{222} \mathrm{Rn}$ ) to another gas (e.g. $\left.\mathrm{CH}_{4}\right)$ on the basis of the physicochemical properties of the gases (Wanninkhof et al., 2009). Although a variety of conceptual models have been introduced over the last decades, the parameterization of $k$ is still under debate (Liss and Merlivat, 1986; Jähne et al., 1987; Wanninkhof, 1992; Nightingale et al., 2000, Sweeney et al., 2007; Weiss et al., 2007; Wanninkhof et al., 2009). For this study, the most recent approximation of Wanninkhof et al. (2009) was used. Equation (3) shows the influence of $u$ on the transfer velocity and methane fluxes in general. To avoid the overestimation of short time changes in wind speed in combination with the infrequently traversing (irregular intervals of transects passing or measuring gaps) by the ferry, methane fluxes were calculated based on monthly averaged parameters to achieve a general pattern. The monthly flux values reported here (see Sect. 3.5) are derived from sea surface methane concentrations $C_{\mathrm{CH}_{4} \text { aq }}[\mathrm{nM}]$ averaged for each leg crossing a selected area (Fig. 1, Table 1) and averaged for each month. Mean monthly atmospheric methane fractions $x_{\mathrm{CH}_{4} \text { atm }}$ [ppm] are derived from the NOAA Station BAL (Baltic Sea, Poland; Dlugokencky et al., 2011). $S c_{\text {sal }}$ was calculated based on temperature and salinity determined like $C_{\mathrm{CH}_{4} \text { aq }}$ (averaged for each leg crossing over the selected areas (Fig. 1, Table 1) and then averaged for each month). Monthly mean wind speed was calculated from the COSMO/EU wind fields averaged over the selected areas.

\subsection{Bottom water temperature}

The water temperature observed near the sea floor is used as a proxy for the temperature of the sediment surface. These data were derived from the HELCOM data set available from the ICES (2011) Oceanographic Database. CTD (Conductivity, Temperature, Density) casts, taken at standard depth levels, supply a sufficiently dense database with more than one thousand samples at a series of stations which characterize the typical conditions in the sub-basins of the Baltic Sea since 1960 . Only data registered within the lowermost $5 \%$ of the water column have been taken into account to calculate the mean water temperature at the seafloor and its range of variation, which in this work is described by the standard deviation and the observed minimum and maximum temperatures.

\subsection{Water column profiles}

Vertical water profiles were taken at station TF0113 in the Arkona Basin. The data set includes 4 profiles collected with a 24 (121) Niskin-bottle rosette water sampler. For continuous CTD profiling a SeaBird SBE911+ system was attached to the underwater unit. After retrieving the sampler on board, oxygen concentrations were determined using Winkler titration (Grasshoff et al., 1999). Methane was extracted from the water sample using the vacuum degassing method and its mole fraction was determined with a gas chromatograph equipped with a flame ionization detector (Keir et al., 2009).

\subsection{Multichannel seismic profile}

To observe free gas accumulations in subsurface sediments, seismo-acoustic data were collected in the Arkona Basin (student cruises of the University of Bremen) using a GI gun with a central frequency of $200 \mathrm{~Hz}$ and a $50 \mathrm{~m}$ long high resolution streamer with 48 channels. The vertical resolution in the seismic profile is approximately 1 to $5 \mathrm{~m}$. Horizontal resolution is determined by the common mid-point (CMP) bin size, which was set to $1 \mathrm{~m}$. Data processing followed a conventional processing flow with special emphasis on the velocity analysis. 


\section{Results and discussion}

The focus in the following sections will be set on the most visited transects I and II, passing west (WoG) and east (EoG) of Gotland (Fig. 1) in 2010. Special emphasis is given to selected key areas (Table 1) in addition to surface methane concentration measurements covering one year. Key controlling parameters such as temperature, wind, and the mixing depth are presented. Data gaps (Fig. 2) due to malfunction/maintenance exist from 9 to 21 April 2010 and from 26 April to 18 May 2010. Smaller data gaps in Fig. 2 are caused by the passing of the ferry along transect III (total of 264 operational days).

First sea surface temperature anomalies were identified indicating local upwelling accompanied by elevated methane concentrations. Highest methane surface values measured throughout the year in the Arkona basin are investigated in regard to the specific environmental setting of shallow gas. A potential linkage between wind and weather-driven hydrostatic pressure changes and methane gas ebullition is suggested. The effects of seasonal sea surface temperature (SST) and mixing depth changes are studied in detail in regard to their control on the surface methane concentration and seaair flux potential. Finally, a seasonal cycle of monthly averaged methane flux calculations will be presented for all key areas including the ice-influenced Gulf of Finland $(\mathrm{GoF})$ area.

\subsection{Overview}

\subsubsection{Regional aspects}

Surface water methane concentrations along transects I and II, passing west and east of Gotland, are shown for all lines gathered in 2010 in Fig. 2, and reveal remarkable regional differences. Strong fluctuations and increased methane concentrations in the westernmost and easternmost parts of each transect have been observed. These regions are covered by both transects in a very similar way. Methane values in the Arkona Basin (Fig. 2, Long: $13^{\circ} \mathrm{E}-14^{\circ} \mathrm{E}$, see Fig. 1 for orientation) range from $3.2 \mathrm{nM}$ to $8 \mathrm{nM}$ (97-270\% methane saturation) with exceptionally high concentrations in February, which will be discussed below (Sect. 3.3). The Gulf of Finland (Long: $22^{\circ} \mathrm{E}-26^{\circ} \mathrm{E}$ ) is characterized by elevated methane concentrations throughout the year compared to the other regions. In fact, the western part of the Gulf of Finland shows a strong variability in methane concentrations during the year, ranging from $3.4 \mathrm{nM}$ (106\% methane saturation) to over $22 \mathrm{nM}$ ( $470 \%$ methane saturation). In the middle of each transect methane concentrations are rather uniform and in general considerably lower. In the area of the island of Gotland (Fig. 2, Long: $18^{\circ} \mathrm{E}-19^{\circ} \mathrm{E}$ ) methane concentrations in the surface water are comparably low, ranging from $3.3 \mathrm{nM}$ (95\% methane saturation) to $4.6 \mathrm{nM}$ (165\% methane saturation). West (WoG) and East of Gotland (EoG; Fig. 2,
Long: $18^{\circ} \mathrm{E}-19^{\circ} \mathrm{E}$ ), episodes of elevated methane concentrations lasting a couple of days were observed during the summer months June till September, when methane values increased more than $3 \mathrm{nM}$ above normal.

\subsubsection{Seasonal aspects}

The seasonal trend of surface water methane concentrations in the Baltic Sea is characterized by high methane concentrations during winter and lower methane values during summer, except for the very shallow areas like the Mecklenburg Bight (MB) or Arkona Basin (see Sect. 3.4). The diverse pattern illustrated in Fig. 2 shows high fluctuations of the methane concentrations during the winter months compared to the rather uniform values in summer. The strongest annual fluctuations were observed in the area of the Gulf of Finland (Fig. 2, Long: $22^{\circ} \mathrm{E}-26^{\circ} \mathrm{E}$ ), where highest methane concentrations (up to $22 \mathrm{nM} ; 470 \%$ methane saturation) were measured in February, decreasing in the time following. Lowest methane values of $3.4 \mathrm{nM}$ ( $106 \%$ methane saturation) were detected during the summer months June till August before concentrations rose again until the end of December.

\subsection{Upwelling}

Upwelling is a typical, well-documented phenomenon in the Baltic Sea (Alenius et al., 1998; Vahtera et al., 2005; Lehmann and Myrberg, 2008; Lips et al., 2009). The process is characterized by winds blowing predominantly parallel to the coast from a favorable direction. Together with the Coriolis effect, this results in a displacement of the upper water body leading to mixing in the water column and upwelling at the coast (Lehmann and Myrberg, 2008). It involves the mixing of dense, cooler and usually nutrientrich water towards the sea surface by replacing the warmer mostly nutrient-depleted surface water (Lehmann and Myrberg, 2008). Depending on the strength and period of the favourable winds, upwelling can range from a small scale coastal event to a large scale phenomenon influencing the open sea. Although this process occurs throughout the year, upwelling plays an essential role in the mixing of the water column during the summer season when additional thermal stratification occurs and nutrients in the surface layers are depleted by algal blooms. Sea surface temperature is a good parameter to indicate upwelling especially during the summer months, when the surface water is warmer than the deeper layers. Then, upwelling can be detected by a local sharp temperature drop in the surface water, which can last a couple of days. A well-developed method to observe this phenomenon, recurring in time and location, is satellite imaging of the sea surface temperature (Siegel et al., 1994, 2005; Lass et al., 2010).

During the measuring campaign with the ferry line Finnmaid, the effect of upwelling on the local surface methane concentrations was recorded several times at different 


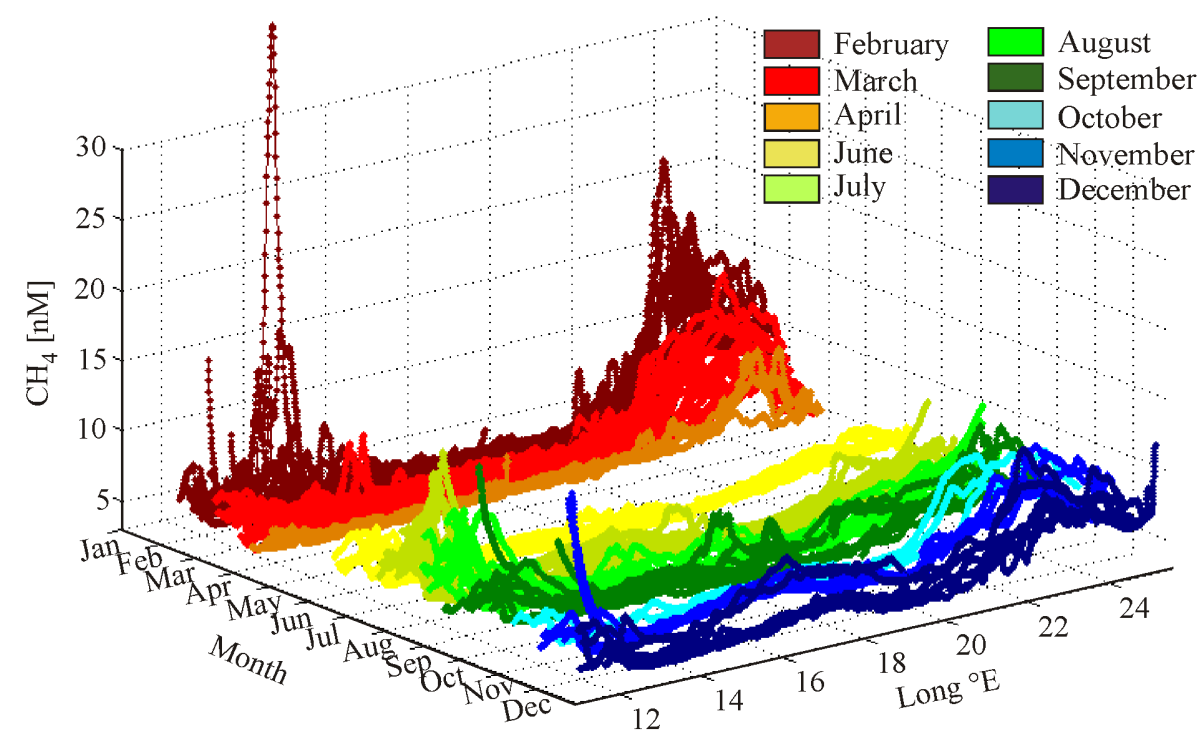

Fig. 2. Methane concentrations of all lines along transect I and II in 2010 color coded for each month. During most of April and May no data could be gathered due to maintenance. Later gaps in the continuous data set are in part due to the passage of the ferry along the transect III.

locations of the Baltic Sea. Especially in the area around the island of Gotland, various events could be observed. In Fig. 3, methane (a), methane saturation (b), partial pressure of carbon dioxide (c) and sea surface temperature (d) are shown for the area north-west of Gotland for the year 2010. Sharp drops of the sea surface temperature (Fig. 3d) on 24 July (light green line) and 3 September (dark green line) can be pointed out with values reaching down well below $5^{\circ} \mathrm{C}$. We highlight these two lines in the following, though various weaker events were observed over the course of the year. For both dates, a property-property plot of methane versus sea surface temperature (Fig. 3e) shows a significant inverse correlation demonstrating the strong coherence of rising cold water masses and increased methane values at the surface (Rehder et al., 2002).

Whereas methane concentrations in July (Fig. 3a, transparent light green lines) vary in general between $3.5 \mathrm{nM}$ and $4.5 \mathrm{nM}$, methane values reach up to $6.8 \mathrm{nM}$ in the surface water on 24 July (Fig. 3a light green line). On 3 September methane concentrations increase even up to $8 \mathrm{nM}$ (Fig. 3a, dark green line). Strong increases during the upwelling events could also be observed in the recorded carbon dioxide concentrations (Fig. 3c) and salinity (data not shown). Usually, all parameters show elevated values for the same time and at the same locations for all recorded upwelling events. The findings reflect the transport of deeper water towards the surface, which are characterized by colder temperatures (Umlauf et al., 2010), enhanced $p \mathrm{CO}_{2}$ from organic matter remineralization (Thomas and Schneider, 1999) and often enhanced methane concentrations (Schmale et al., 2010). Methane saturation values (Fig. 3b) increase during the major upwelling events in July and September, but the recorded sig- nals vary significantly from the methane signal (Fig. 3a). Although upwelled waters are enriched in methane, the increase in saturation values is less pronounced than the methane signal (Fig. 3a) because lower temperatures imply higher solubility. During the upwelling event on 3 September methane values reach $8 \mathrm{nM}$ and oversaturation of $194 \%$ at water temperatures of $3.6^{\circ} \mathrm{C}$ (Fig. 3a and b dark green line) was observed. With a water temperature of $22^{\circ} \mathrm{C}$, this surface methane concentration would reach over saturation values of more than $300 \%$. Still, the transport of deeper water towards the surface and the increase of the sea surface methane concentration change temporally the saturation of methane in the surface water, influencing the emission of methane towards the atmosphere, which will be discussed below. Unfortunately, due to the changing frequency of transects passing the western coast of Gotland no continuous data recording could be achieved in this area. Therefore, the persistence of the upwelling-induced methane (and carbon dioxide) oversaturation and the timeframe for dilution/evasion to the atmosphere could not be tracked.

The different signal widths of the corresponding curves for carbon dioxide and methane, shown in Fig. 3, need to be highlighted. The crossing of the investigated area northwest of Gotland had a duration of approximately $4 \mathrm{~h} 15 \mathrm{~min}$ on 24 July (Fig. 3, outstanding light green), and $5 \mathrm{~h} 15 \mathrm{~min}$ on 3 September (Fig. 3, outstanding dark green line). Although both records show a similar line characteristic, the methane signal is wider than the corresponding records of carbon dioxide. To a large extend, the different shapes of the methane and carbon dioxide curves might reflect the different response times of the system for the two gases, with the time constant for $\mathrm{CH}_{4}$ approximately four times 

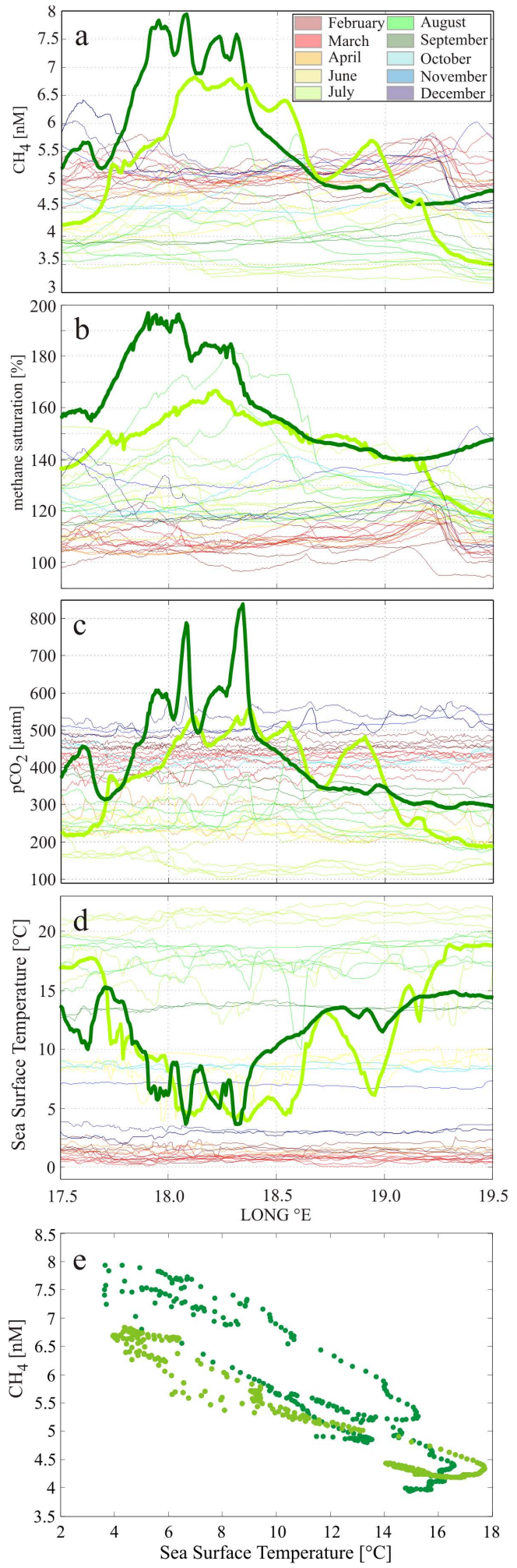

Fig. 3. (a) Methane, (b) methane saturation, (c) carbon dioxide and (d) sea surface temperature of the area West of Gotland for the year 2010. All data in transparent thin lines color coded for each month. Two significant upwelling events in July and September are highlighted with outstanding light green (24 July) and dark green (3 September) lines. For these dates, methane versus sea surface temperature is shown using the same color coding (e). longer than for $\mathrm{CO}_{2}$ (for detailed discussion, see Gülzow et al., 2011). On the other hand, methane concentrations and carbon dioxide partial pressures do not have to be directly related. Though both properties generally increase underneath the mixed layer (Thomas and Schneider, 1999; Schmale et al., 2010), the $p \mathrm{CO}_{2}$ increase, mostly resulting from organic matter degradation, will start immediately underneath the mixed layer, while stronger enhancement of methane is generally observed at greater depth. The oval shaped characteristic of the plot of methane concentration versus sea surface temperature and methane (Fig. 3e), can be explained by the faster response time of the temperature signal compared to the slower MCA-signal in respect to changing water masses. The signal reflects the "in and out"- passage through the inhomogeneous upwelling water mass.

\subsection{Pressure-induced liberation of methane from the seafloor}

On 2, 4 and 5 February, extraordinarily high methane concentrations were measured in the surface waters of the Arkona Basin rising up to $38 \mathrm{nM}$ ( $832 \%$ methane saturation), $15 \mathrm{nM}$ (321\% methane saturation) and $16.5 \mathrm{nM}(360 \%$ methane saturation), respectively (Fig. 4). Elevated methane concentrations could be measured until 6 days after the event, with decreasing values until concentrations prior to the event were reached. These exceptionally high methane concentrations in the surface water were accompanied by a longer period of strong winds, starting in the middle of January, which resulted in an oscillation of the sea level of almost $1.5 \mathrm{~m}$ within a day in the Arkona Basin (Fig. 4, gray line, station Sassnitz, Bundesanstalt für Wasserbau BAW). Further, the windinduced mixing depth of the water column was calculated to reach down to the sediment surface at $45 \mathrm{~m}$ depth during this period (Fig. 4, blue line). The data can be interpreted with additional data of dissolved methane measurements in the water column sampled during 4 research cruises between December 2009 and August 2010 (Fig. 5) in the Arkona Basin at station TF0113 (Lat: $54.92^{\circ} \mathrm{N}$; Long: $13.50^{\circ} \mathrm{E}$, for location see Fig. 1). Methane concentrations in the upper water layer were approximately 10 times higher than usual on 28 January, with concentrations around $50 \mathrm{nM}$ down to $30 \mathrm{~m}$ depth (Fig. 5) and increasing towards the seafloor to a maximum concentration of $420 \mathrm{nM}$ at $40 \mathrm{~m}$ depth. The parameters salinity, oxygen and temperature indicate mixing of the entire upper water column by uniform values down to nearly $40 \mathrm{~m}$ depth in accordance to the model-derived mixing depth (Fig. 4). Further towards the seafloor a gradual increase in temperature and salinity marks the existence of a narrow bottom layer. In contrast, the average methane concentration in the water column in December 2009 at Station TF0113 (Fig. 5) was $7.7 \mathrm{nM}$. Methane profiles taken during cruises in July and August 2010 show similar low methane concentrations of $5.1 \mathrm{nM}$ and $10.8 \mathrm{nM}$ on average for the mixed layer, respectively. Turbidity signals of station TF0113 (data not 


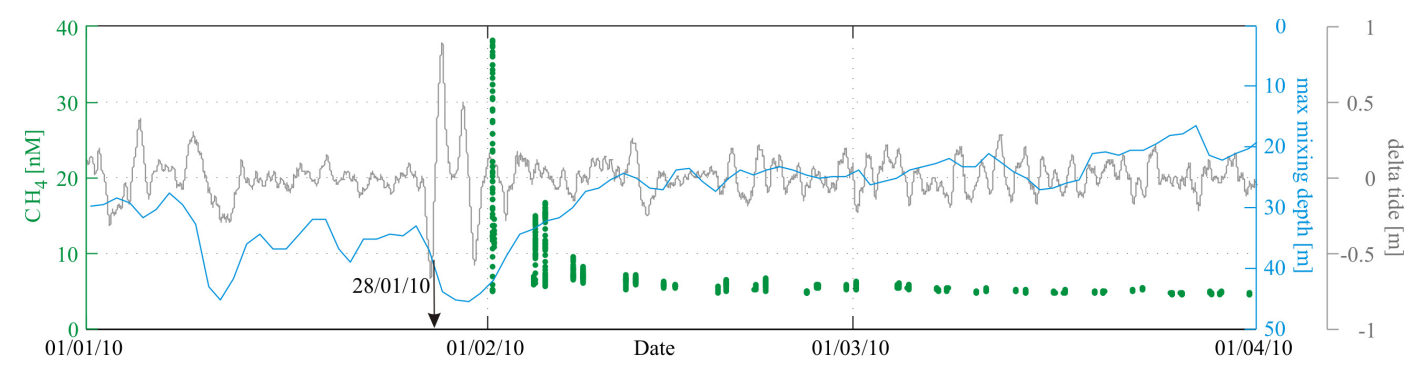

Fig. 4. Data from a three month survey of the Arkona Basin. Sea surface methane concentrations (green dots, representing measured methane concentrations along each leg crossing the selected area "Arkona Basin", Table 1), daily maximum mixing depths (blue line) and sea level data (gray line, measured at station Sassnitz, Bundesanstalt für Wasserbau). Delta tide indicates the gradient of oscillation of the sea level around 0 .

shown) on 28 January increase significantly from $0.4 \mathrm{NTU}$ (Nephelometric Turbidity Unit, average of upper $40 \mathrm{~m}$ water column; data not shown) to $1.02 \mathrm{NTU}$ in the bottom water layer, indicating enhanced shear stress at the sediment-water interface. For comparison, turbidity measurements at this station on 1 August show values below $0.5 \mathrm{NTU}$ for the entire water column.

Based on acoustic data collected throughout the Arkona Basin, free gas accumulations in the Holocene mud are known to be widespread (Mathys et al., 2005; Thießen et al., 2006). While these gas layers originate from organic matter degradation within the mud where gas bubbles are efficiently trapped, only one seabed feature has been found in the region so far, which may indicate focused gas escape from the subsurface. This is shown in the seismic section in Fig. 6 (Lat: $54.90^{\circ} \mathrm{N}$ Long: $13.61^{\circ} \mathrm{E}$ ), where a subtle $1 \mathrm{~m}$ deep depression in the seafloor of slightly elongated shape with a maximum diameter of $\sim 120 \mathrm{~m}$ is associated with a strong, but reversed polarity seafloor return and structural disturbance beneath. This indicates the actual presence of free gas at the seabed, as the phase reversal is a result of the decrease of bulk density and/or seismic velocity in the gascharged sediment. The pockmark is surrounded with high amplitude seafloor reflections on both sides forming a few hundred meter wide ring (data not shown). The deeper one of the double reflector near the seafloor represents the top of the gas-charged sediment layer. A further distinct reflector with reversed polarity appears at $23 \mathrm{~ms}$ TWT b.s.f. (two way travel time below seafloor) and at 44 ms TWT b.s.f., a strong reflection marks a density/velocity increase from glacial clay to compacted till or Cretaceous basement. Evident is the structural disturbance in the vicinity of the pockmark, as well as a positive relief of a sedimentary unit between 78 and $88 \mathrm{~ms}$ TWT. Together with a potential fault system at $1100 \mathrm{~m}$ offset, we see typical indications for deeper gas migration (absence of reflections, circular anomaly, anomalous sedimentary unit), which distinctly differs from the typical appearance of shallow gas elsewhere in the Baltic Sea.

TF0113 is located only 6.5 nautical miles apart from this feature and, in combination with the recorded sea level, we suggest a pressure-induced seepage event (Wever et al., 2006; Schneider v. Deimling et al., 2010) to have caused extraordinarily high methane values in the entire water column. It can be assumed that the oscillation of the sea level and the resulting sudden pressure drop lead to the abrupt transition of dissolved (pore water) methane into free gas followed by ebullition of free gas to the water column, or by a pressure-induced (amplified by wind and waves) pumping impulse on the pore water of the sediment and thus, seepage of methane-enriched water to the water column. For the situation at station TF0113, both mechanisms would produce the same signal with the observed enhanced but uniform distribution of methane due to the almost complete mixing of the water column (Fig. 5). In contrast, gas transport and advection/diffusion of dissolved methane can be clearly distinguished in waters with a density stratification, which greatly reduces diapycnal mixing of the water and thus, the vertical transport of dissolved constituents, while not hindering gas bubble mediated transport (Schneider v. Deimling et al., 2011).

\subsection{Seasonal patterns of $\mathrm{CH}_{4}$ concentration and oversaturation in the main basins of the Baltic Sea}

The annual cycles of surface methane concentration and oversaturation show some distinct seasonal trends in the individual basins, which in the following sections are discussed in the framework of the key controlling parameters, e.g. sea surface temperature, mixing depth, sea-air exchange, and potential direct connection of the upper water body to the sediment (Fig. 7, Table 1).

\subsubsection{Water temperature}

The average sea surface temperature of the Baltic Sea ranged from $0{ }^{\circ} \mathrm{C}$ in February to almost $23^{\circ} \mathrm{C}$ in July in 2010 with strong regional differences (Fig. 7, red lines). Strongest fluctuations of sea surface temperature were observed in the area of the Gulf of Finland with widespread ice-coverage during February and March. Highest surface temperatures in the Gulf of Finland were measured in July reaching up to $24^{\circ} \mathrm{C}$. 

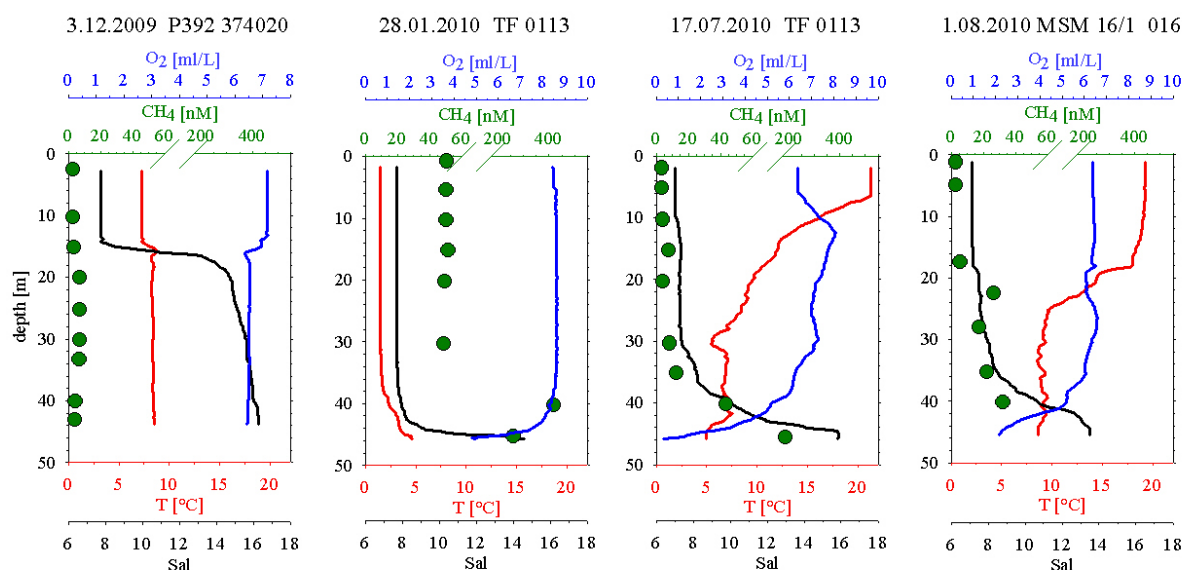

Fig. 5. Data of water column properties and methane concentration of profiles at station TF0113 taken during four cruises in December 2009 (Poseidon P392), January 2010 (Heincke 06HK 1001), July 2010 (Alkor 06 AK1003) and (Maria S. Merian MSM 16/1). Methane concentration (green dots), temperature (red line), salinity (black line) and oxygen values (blue line). The sampling dates of the profiles are marked as well in time scale of the subplot AB in Fig. 7.

Sea surface temperature of the Gotland Basin (GB) ranges from $4{ }^{\circ} \mathrm{C}$ to $21{ }^{\circ} \mathrm{C}$ in comparison. The rise in temperature mainly takes place between early April and July. During this period, a continuous increase in methane saturation was observed (Fig. 7, black broken line) in all basins.

The temperature strongly influences the methane solubility in water and seawater, in which on average $2.4 \%$ less methane can be dissolved for each degree of temperature rise (Wiesenburg and Guinasso, 1979). Thus, a water mass which is warmed will be increasingly oversaturated with respect to the atmosphere without an increase in the absolute concentration, in accordance to our observations. However, the induced oversaturation will stimulate the transfer of methane to the atmosphere (see Sect. 3.5 and Fig. 8).

The warming of the sea surface beginning in April leads to the warming of parts of the water column below, and can also cause warming of the sediments, especially in shallow regions with a temporarily well-mixed water column. The water temperature observed near the sea bottom is used as a proxy for the temperature of the sediment surface. Bottom water temperatures in the Arkona Basin, for example, show annual fluctuations between $-0.32^{\circ} \mathrm{C}$ (minimum) and $15.6^{\circ} \mathrm{C}$ (maximum; ICES, 2011). In deeper basins the annual fluctuation of the surface sediment temperature can be expected to be much smaller than the fluctuations at the sea surface (Mogollón et al., 2011). The sediment temperature influences the solubility of methane in pore water and the depth of the shallow gas boundary layer (Wever et al., 2006). With the warming of the sediment it can be expected, that less methane is solved in the pore water and saturated pore waters might get oversaturated, resulting in a lower depth of the free gas boundary layer or in an increased emission rate of sedimentary methane towards the water column. Further, temperature is a key control for the production of methane by methanogenic microbes (Heyer and Berger, 2000).

\subsubsection{Stratification}

The Baltic Sea can be distinguished in areas with permanent (e.g. GB) and temporal stratification (e.g. AB, GoF; Feistel et al., 2008). The warming of the surface water layers lead to a stratification of the water column and the formation of the temporal thermocline during the summer months. The stratification, beginning in April, separates the water column above the permanent halocline (where existent) into two sublayers with different physical properties, the lower one mostly defined by the winter surface water generated during maximum mixing depth in winter. Like the halocline, the thermocline reduces vertical mixing and the methane transport in particular between the deep water masses and sediment to the surface water. The deeper bottom layers, disconnected from the surface, start to get enriched in methane due to the steady supply of methane from the seabed or the methane-enriched water below the halocline. In contrast, the surface water gets depleted in methane due to loss to the atmosphere by sea-air exchange, in part driven by the temperature-induced decreasing solubility.

\subsubsection{Wind, mixing depth, and sea-air exchange}

The sustainability of the stratification of the water column depends on the annual changing wind energy and the resulting mixing intensity and the temperature-gradient-driven heat exchange. In general, wind velocities in the Baltic Sea are higher during the winter season and lower during the summer months. As a consequence, the depth of the mixed layer is shoaling until midsummer, leading to the formation of water layers with different properties (including methane 


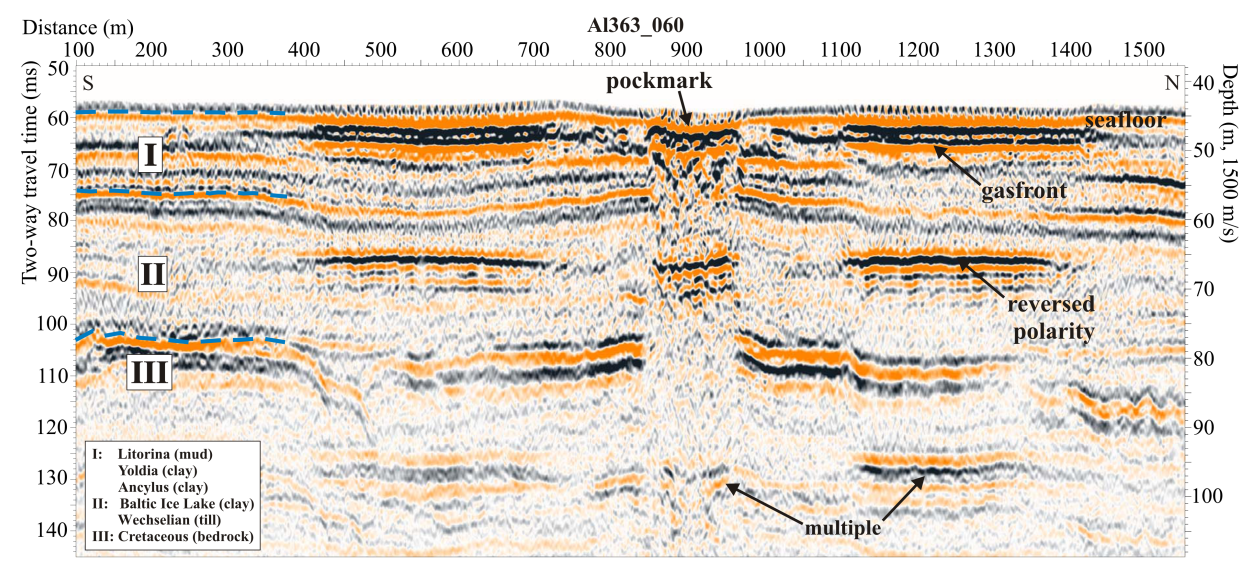

Fig. 6. Multichannel seismic profile showing a pockmark and its vicinity in the Arkona Basin. The seismic section is running from south (Lat: $54.90^{\circ} \mathrm{N}$, Long: $13.61^{\circ} \mathrm{E}$ ) to north (Lat: $54.91^{\circ} \mathrm{N}$, Long: $13.61^{\circ} \mathrm{E}$ ). The presence of free gas beneath the seabed is indicated by the reversed polarity compared to the normal polarity of the seafloor outside the pockmark. The blue lines indicate layer boundaries.

concentrations). After reaching a minimum depth, the mixing depth deepens again by wind stirring and thermal convection until it reaches its maximum in winter (Fig. 7, blue lines). In the shallower and not permanently stratified basins, this can lead to occasional complete homogenization of the water column.

The wind speed also controls the gas transfer velocity $k$ (which in this work scales with $u^{2}$; Eq. (3), Wanninkhof et al., 2009), and the air-sea exchange of methane (see Sect. 2.5). Figure 9 shows $k$, which is low from April till July (main warming of the sea surface) and increases in midsummer. A higher transfer velocity fosters the relaxation of the disequilibrium between surface water concentrations and atmospheric equilibrium. The mixing depth determines the thickness of the water body from which a net sea-air flux can be sustained. Thus, at a given $k$, relaxation towards methane equilibrium increases with increasing mixing depth.

\subsubsection{Methane concentrations according to seasonal changes}

The patterns of sea surface methane during 2010 in the different sub-basins result from the combination of the influencing parameters temperature and wind with the conveyed controls of mixing depth, stratification and change of the gas transfer velocity as described above. In spite of data gaps due to maintenance problems of the measuring system in April/May, the general trend of the surface methane distribution can be perceived and is confirmed by measurements of the year 2011 (data not shown). The combination of the controlling factors result in distinct patterns of oversaturation and methane flux into the atmosphere in different sub-regions of the Baltic, in particular contrasting areas with at least occasional interaction between the sediment, deeper water and surface water (e.g. $\mathrm{MB}, \mathrm{AB}$ ), and areas with a permanent decoupling of the sediment and sea surface due to a permanent halocline (e.g. GB, WoG, BB).

The winter period January-March is characterized by low sea surface temperatures and high wind velocities. Highest measured methane concentrations were recorded during this winter period especially in the regions of Arkona Basin, Bornholm Basin and Gulf of Finland (Fig. 7, green dots, and three day average: black solid line) with maximum values in January and declining concentrations towards March (with the exception of the GoF, see below). A high wind-induced energy input to the water column in combination with cooling from the atmosphere results in a maximum mixing depth and the mixing of the entire water column down to the sediment in some of the regions of the Baltic Sea, except for regions with a permanent halocline (e.g. GB). The intense mixing accelerates the transport of methane from the sediment to the sea surface. Enhanced transport from the bottom layer and sediment surface into the water column can occur in completely unstratified conditions because of enhanced shear stress at the sediment-water interface. On the contrary, strong wind forces enhance the gas transfer velocity at the air-sea boundary, leading to an overall decrease of methane in the surface water later in winter (Fig. 7, green dots and black solid line).

During the period from early April till July/August, sea surface temperatures increase in all regions of the Baltic Sea (Fig. 7, red lines) and the mixing depth decreases with the development of the thermocline and summer stratification (Fig. 7, blue lines). In general, the stratification of the water column hampers the methane transport between deeper layers and the sea surface in the Baltic Sea (Schmale et al., 2010). The temperature-driven solubility decrease leads to an increase in methane saturation values in all regions of the Baltic Sea (Fig. 7, black broken lines), which could account for up to approximately $50 \%$ of additional methane saturation, assuming a temperature 

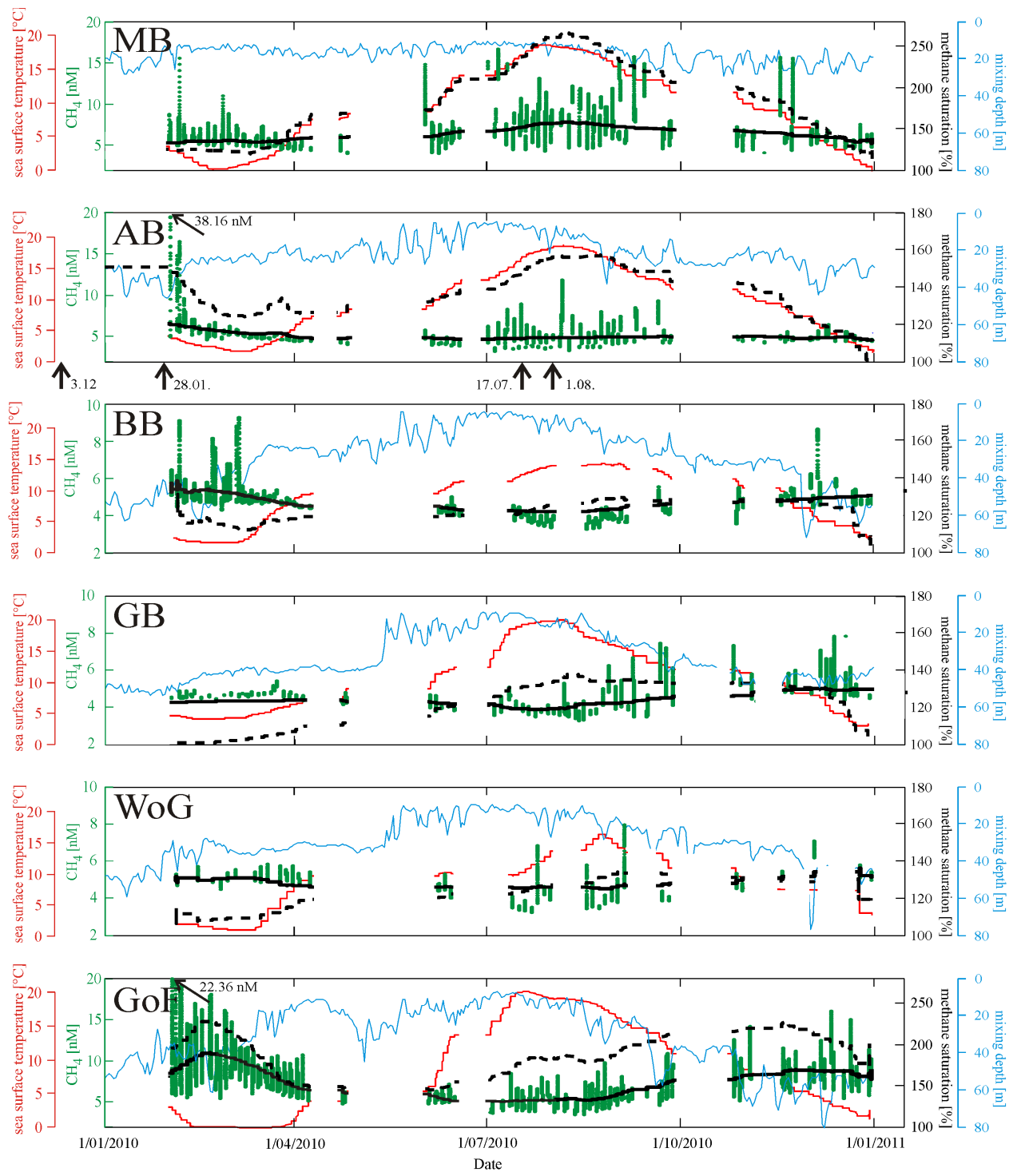

Fig. 7. Compilation of various data sets for the interpretation of the seasonal methane distribution. Sub-charts show measured time series of methane concentrations (green points) for each passing of the selected area (Table 1), its three day average (black solid line), maximum mixing depth (blue line, daily average), methane saturation (black dotted line, three day average), and sea surface temperature (red line, three day average) for Mecklenburg Bight (MB), Arkona Basin (AB), Bornholm Basin (BB), Gotland Basin (GB), West of Gotland (WoG) and Gulf of Finland $(\mathrm{GoF})$. The arrows beneath subplot $\mathrm{AB}$ indicate the sampling date of the water column profiles shown in Fig. 5. Arrows in subplot $\mathrm{AB}$ and $\mathrm{GoF}$ show maximum values of methane concentration. Note the two different scales for methane concentration and methane saturation used for the individual subplots.

increase of $18^{\circ} \mathrm{C}$ and constant methane concentrations in the surface water during this period $(2.4 \%$ methane saturation for each degree temperature, loss to the atmosphere neglected). The emission of methane to the atmosphere is reduced due to lower wind velocities and gas transfer coefficients (Fig. 9) so that a slight oversaturation is sustained although the sea-air flux tends to force the surface water methane concentration towards equilibrium. During this period, the constant (though small) flux of methane to the atmosphere and the inhibited replenishment from deeper wa- ter layers due to summer stratification lead to the decrease in methane concentration in the surface layer. Deeper layers below the thermocline are characterized by steady enrichment of methane by the sediment or mixing with methane-enriched water below the halocline, forming a reservoir of methane. The reduced mixing depth and stratification of the water column allows for the development of strong methane gradients within the upper $20 \mathrm{~m}$ (e.g.: AB, profile of 1 August 2010, Fig. 5, with $3 \mathrm{nM}$ methane at $2 \mathrm{~m}$ and $26 \mathrm{nM}$ methane at $22 \mathrm{~m}$ depth). 


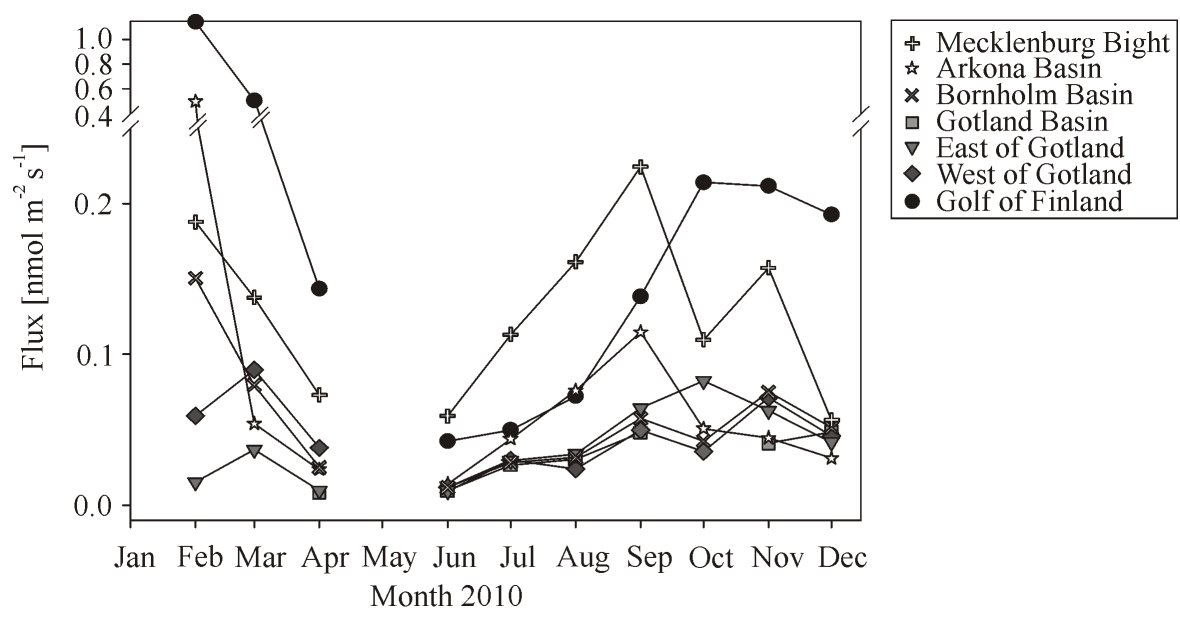

Fig. 8. Methane fluxes $F$ [nmol m${ }^{-2} \mathrm{~s}^{-1}$ ] calculated as monthly average for selected areas of the Baltic Sea using the equation described in Wanninkhof et al. (2009). Atmospheric methane data from the NOAA station in Poland were used for the calculation of the equilibrium concentration.

After its maximum in August, sea surface temperature starts to decrease around September (Fig. 7, red lines), causing an increase in the solubility of methane in the water. Winds intensify, resulting in deeper mixing of the water column. With increasing mixing depth, water layers with elevated methane content are mixed to the surface, increasing the surface methane concentrations. For this period, strong regional differences of the methane saturation can be pointed out between the shallow regions $(\mathrm{MB}$ and $\mathrm{AB}$ ) and the deeper regions of the Baltic Sea, e.g. Gotland Basin or Gulf of Finland. In the deeper basins (e.g. GB, BB, WoG, GoF), the deepening of the mixed layer leads to entrainment of methane-enriched deeper waters into the surface layer, increasing methane concentrations. Despite the deepening of the mixing depth in the Gotland Basin, the stratification of the water column sustains, and the deep water volume with high methane values as described in Schmale et al. (2010) is not mixed to the surface. Cooling of the mixed layer partly dampens the effect of increasing concentrations on the oversaturation. The latter, in connection to enhanced wind speeds (and thus transfer velocities) lead to enhanced flux towards the atmosphere (see Sect. 3.5). Interestingly, the net result of these co-acting processes for Bornholm Basin, West of Gotland and Gotland Basin is an increase in concentrations in connection to a relatively constant oversaturation until the end of the year.

The Gulf of Finland generally follows a similar trend, but methane concentrations increase more strongly and oversaturation increases steadily towards the end of the year with increasing mixing depth. This is consistent with the finding that the sub-thermocline waters in the Gulf of Finland are more enriched in methane than in the other central basins addressed above (Schmale et al., 2010). Another interesting finding is that the highest concentrations and levels of over- saturation are found in February/March, though the maximum mixing depth has been reached before, an effect of partial ice coverage. We assume that methane concentrations and saturation values of more than $200 \%$ in this region in late winter indicate methane accumulations in the water column under the ice cover (Berger and Heyer, 1990) which result in elevated emission rates (discussed below) in ice free areas of the Gulf of Finland due to the main water currents along the coast (Alenius et al., 1998). However, the influence of ice coverage on sea surface methane concentrations in the Gulf of Finland needs to be investigated in more detail in the future.

An exception from these annual patterns of methane surface concentration and oversaturation occurs in the very shallow area of the Mecklenburg Bight and, to a lesser extent, the Arkona Basin. In both basins, methane oversaturation strongly follows the trend of sea surface temperature. In the Mecklenburg Bight, methane concentrations increase during the summer, reaching a maximum in August and leading to the high saturation value of $290 \%$ (Fig. 7). We suggest that wind-induced mixing remains relevant for the transport of methane from the sediment and that summer stratification is neither capable nor sufficient to suppress the methane transport from the sediment to the sea surface in these shallow basins for longer timescales. The observed high fluctuations in methane concentrations throughout the year (MB, Fig. 7, green dots) can be related to short-time wind events with enhanced mixing of the water column. Additionally, the importance of boundary mixing is enhanced and the volume of water below the thermocline will always be small in relation to the volume of the mixed surface layer in MB. As a consequence, no build up of a large methane inventory can counteract the annual variation of solubility by temperature changes, which is mirrored in the parallel trends of sea 


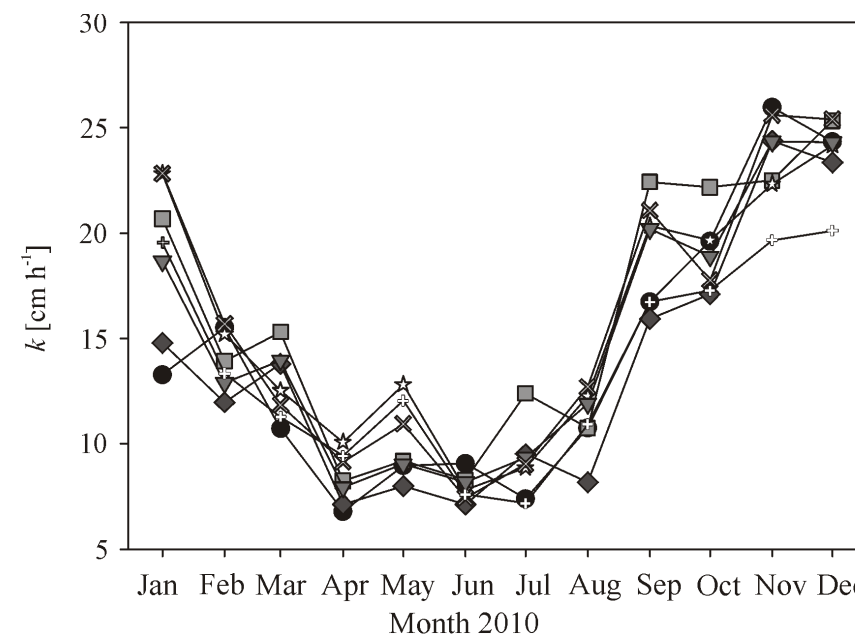

$$
\begin{array}{|l|}
* \text { Mecklenburg Bight } \\
\star \text { Arkona Basin } \\
\times \text { Bornholm Basin } \\
\square \text { Gotland Basin } \\
\nabla \text { East of Gotland } \\
\diamond \text { West of Gotland } \\
\bullet \text { Golf of Finland } \\
\hline
\end{array}
$$

Fig. 9. Transfer coefficient $k$ during 2010 for selected areas of the Baltic Sea with $k=0.24 \cdot u^{2}$ after Wanninkhof et al. (2009); whereas $u$ is defined as daily average wind speed in $\left[\mathrm{m} \mathrm{s}^{-1}\right]$.

surface temperature and methane saturation. However, the amplitude of the seasonal trend is far too large to be caused by the temperature effect alone, even considering the reduced sea-air exchange from spring to summer. Apparently, the source strength for methane into the waters of the Mecklenburg Bight is modulated by sediment temperature. The variation of water temperature at sea bottom from $0{ }^{\circ} \mathrm{C}$ to above $15^{\circ} \mathrm{C}$ (ICES, 2011) is comparable to sea surface temperature changes (Fig. 7). Potential consequences are increased microbial methanogenesis due to increasing sediment temperatures as well as higher methane emissions from the sediment to the water column (Heyer and Berger, 1990, 2000), because of the solubility effect on pore waters and shallow gas accumulations.

The Arkona Basin can be characterized as an intermediate between shallow regions like the Mecklenburg Bight and deeper regions like the Bornholm Basin or Gulf of Finland. The Arkona Basin is deeper than the Mecklenburg Bight and therefore the direct influence of the sediment and bottom water towards the surface layer as described above is assumed to be less dominant than in the Mecklenburg Bight, resulting in lower methane saturation values not exceeding $160 \%$ in August (Fig. 7, black broken line). It is notable, that the maximum methane saturation value in the Arkona Basin is reached later than in the Mecklenburg Bight, and that the duration of this peak is longer (several weeks) than in the Mecklenburg Bight (couple of days). Accordingly, the mixing depth increases during this period by more than $10 \mathrm{~m}$ (August-September) until it reaches the bottom layer and the sediment in November. Similar to the Mecklenburg Bight but little delayed in time, saturation values start to decrease in September according to the temperature-induced solubility effect until lowest saturation values are reached by December. This leads to the assumption that no methane reservoir could be established in the water column of the Arkona Basin like in the Bornholm Basin or Gulf of Finland, where saturation values remain elevated until the following spring season. Comparing the volume of water below the thermocline of shallow regions like the Mecklenburg Bight to deeper regions like the Bornholm Basin or Gulf of Finland, deeper basins contain a much larger volume of water, implying a larger methane-enriched reservoir which can be mixed to the surface. It is remarkable that the three day average of methane concentration (Fig. 7, black solid line) in the Arkona Basin shows almost constant methane values in the surface water from April until December. That shows the intermediate character of the Arkona Basin, being between the deeper basins with methane concentration minima in summer and the shallow region of the Mecklenburg Bight with maximum concentrations during this period.

A basic proof of concept for our interpretation of the processes after the peak of the summer stratification based on a mass balance approach is given in Sect. 3.6 for the Arkona Basin.

\subsection{Flux - methane emissions to the atmosphere}

Our data show that the Baltic Sea remains a source for atmospheric methane with a positive sea-air methane flux throughout the year in all regions (Fig. 8). Average wind speeds and thus, transfer velocities, show a similar pattern for all areas in the Baltic Sea, with decreasing values during the spring period, very low values during the summer period, a sharp increase in August and persistent high values in fall and early winter. Figure 9 shows calculated transfer velocities $k$ (after Wanninkhof et al., 2009) for methane in the Baltic Sea for selected areas in 2010.

Methane fluxes during the period from April to August remain in generally low, ranging from 0.008 to $0.162 \mathrm{nmol} \mathrm{m}^{-2} \mathrm{~s}^{-1}$ in comparison to the period 
September-November with fluxes ranging from 0.036 to $0.225 \mathrm{nmol} \mathrm{m}^{-2} \mathrm{~s}^{-1}$ (Fig. 8). The general increase of methane fluxes from June-August can be explained with the temperature induced solubility effect and the resulting increasing methane oversaturation in combination with a relatively low and uniform average gas transfer coefficient. All basins show a considerable increase in the calculated methane flux in August (Fig. 8) as a consequence of the transition to the regime of high wind velocities (see $k$, Fig. 9).

Beginning in October, strong differences in the general flux distribution occur, with decreasing values in the Mecklenburg Bight and Arkona Basin compared to relatively stable or increasing values in deeper regions like Bornholm Basin, West of Gotland, East of Gotland, or Gulf of Finland, a consequence of the regional differences in the seasonal development of methane oversaturation as discussed in Sect. 3.4. Whereas fluxes in the areas of the Bornholm Basin, Gotland Basin and around the island of Gotland show a very similar pattern, fluxes in the area of the Mecklenburg Bight and the Gulf of Finland deviate significantly. The Mecklenburg Bight shows generally elevated methane fluxes compared to the Arkona Basin, Bornholm Basin, Gotland Basin, West of Gotland, and East of Gotland, and significantly outstanding methane fluxes during the period of JuneSeptember. This can be explained by the mechanisms causing increasing surface water concentrations until late summer discussed in Sect. 3.4, leading to increasing emission rates to the atmosphere. Methane fluxes in the Mecklenburg Bight drop from $0.225 \mathrm{nmolm}^{-2} \mathrm{~s}^{-1}$ in September to $0.108 \mathrm{nmolm}^{-2} \mathrm{~s}^{-1}$ (Fig. 8) in October and further on until December despite of an increase of $k$, again mirroring the (here decreasing) trend in sea surface methane concentration during this period. For the deeper basins, the constantly high average transfer velocities in combination with the relatively stable oversaturation sustained by mixed layer deepening lead to the stable enhanced methane sea-air fluxes from September until the end of the year (Fig. 8, BB, GB, WoG, EoG). The Arkona Basin is considered as an intermediate between the very shallow Mecklenburg Bight and the deeper basins. Here, a methane flux of $0.497 \mathrm{nmolm}^{-2} \mathrm{~s}^{-1}$ in February might have been caused by the described seepage event in the Arkona Basin (see also Sect. 3.3). The Gulf of Finland shows comparable high flux values throughout the year (Fig. 8). Gassy sediments and temporal anoxic conditions in bottom layers of the Gulf of Finland during the summer period (Alenius et al., 1998) result in high amounts of methane (dissolved in the deeper layers), which are mixed to the surface in autumn and winter. The origin of extraordinary methane fluxes of $1.145 \mathrm{nmolm}^{-2} \mathrm{~s}^{-1}$ and $0.506 \mathrm{nmol} \mathrm{m}^{-2} \mathrm{~s}^{-1}$ in February and March, respectively, have to be regarded with caution because of the potential role of sea ice. The ice coverage starts at the Finnish coast line of the Gulf of Finland in January and reaches its largest expansion during March (data not shown, Swedish Meteorological and Hydrological Institute, SMHI). During the pe- riod of ice coverage no or very limited sea-air exchange of methane can be expected. Nevertheless, the southwestern part of the Gulf of Finland remained principally ice free during the winter period in 2010 just as the main ship traffic route of Helsinki (SMHI). Here, changing conditions of drifting ice shields with suppressed sea-air exchange and open water with high dissolved methane concentrations in the surface water (Fig. 2) as well as high wind speeds and transfer velocities (Fig. 9) can be assumed to influence methane fluxes to the atmosphere significantly but will need further investigation.

For the area of the Gotland Basin very low monthly averaged sea-air fluxes with $0.0008 \mathrm{nmolm}^{-2} \mathrm{~s}^{-1}$ in December 2009 (data not shown) and $0.008 \mathrm{nmol} \mathrm{m}^{-2} \mathrm{~s}^{-1}$ in April 2010 were calculated (Fig. 8). Looking at averaged methane saturation values of single lines crossing the Gotland Basin in April, values of $96 \%$ saturation with respect to the atmosphere were calculated. Observations in 2011 show saturation values of $94 \%$ in February and April (data not shown), indicating that during the period December-April the direction of the net flux for methane might change frequently in the Gotland Basin. However, this occasional undersaturation of methane can be explained by the enhanced solubility of methane at lower temperatures and has only little effect on the general flux trend in this region.

Bange et al. (1994) calculated methane sea-air fluxes during July/August to be $1.17-13.9 \mathrm{nmolm}^{-2} \mathrm{~s}^{-1}$ and $0.11-$ $0.17 \mathrm{nmol} \mathrm{m}^{-2} \mathrm{~s}^{-1}$ during February, indicating a larger flux during summer than during winter. Their flux estimates are based on results of atmospheric and dissolved methane concentrations determined using an automated gas chromatographic system during two Baltic cruises (Southern Belt Sea, AB, BB, GB) in February 1992 (63 stations) and July/August 1992 (23 stations) following Liss and Merlivat (1986). The large data set underlying the flux estimations presented here provides monthly mean methane fluxes for the whole year 2010. Methane fluxes in February and July/August amounted to $0.151-0.080 \mathrm{nmolm}^{-2} \mathrm{~s}^{-1}$ and $0.010-0.076 \mathrm{nmol} \mathrm{m}^{-2} \mathrm{~s}^{-1}$ for the Arkona Sea, Bornholm Sea and Gotland Sea. The summer fluxes calculated here are significantly lower than those presented by Bange et al. (1994). General seasonal changes of methane saturations with low values during winter (e.g. 107\% BB) and higher values during summer (e.g. $157 \%$ BB) could be confirmed in this study (e.g. $116 \%$ February $-134 \%$ July/August, BB). Still, averaged methane supersaturation values of $3757 \%$ based on measurements at two stations during the summer sampling campaigns by Bange and coworkers disagree with results presented in this study, showing averaged methane saturation values of $290 \%$ for the Mecklenburg Bight for July and August. We therefore assume that estimated summer fluxes were overestimated by Bange et al. (1994). Further, Fig. 8 shows that the seasonality of methane fluxes is characterized by maximum values during winter and lowest values during summer for the Baltic Sea. 


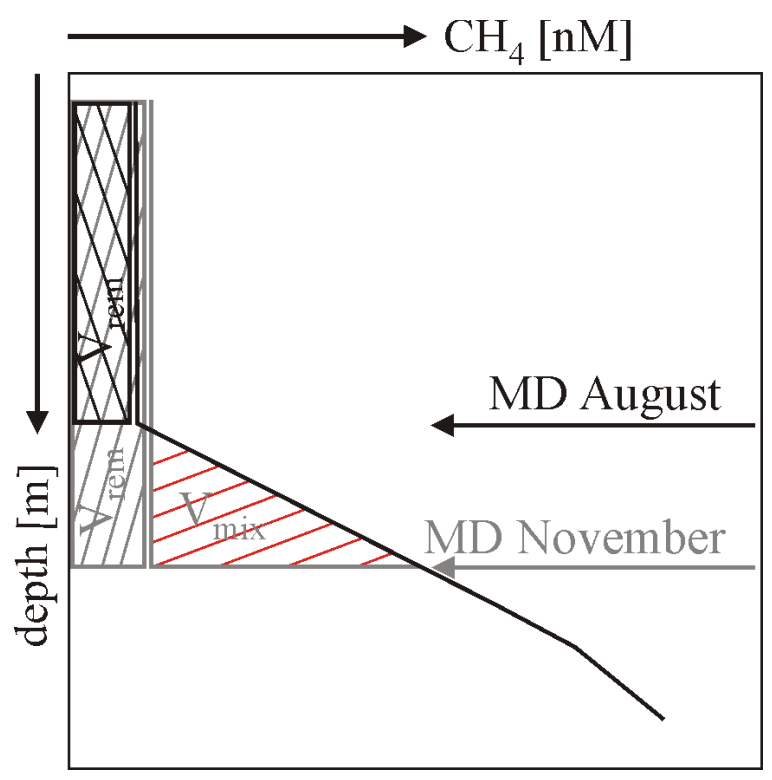

Fig. 10. Scheme illustrating a methane concentration profile (black solid line) in August and the deepening of the mixing depth (MD) from August (black arrow) to November (gray arrow). The amount of dissolved methane remaining in the homogeneous mixed upper water column $V_{\text {rem }}$ is estimated according to the surface methane concentration measured in August and November, respectively. The amount of dissolved methane $V_{\text {mix }}$ is mixed into the upper water column during the period August-November.

\subsection{Methane mass balance during the period of mixed layer deepening}

As proof of concept, a rough methane mass balance for the development of the methane concentration in the mixed layer, the water below and the sea-air flux for the period of mixed layer deepening has been calculated using the water column methane profiles of station TF0113 (1.8.2010, AB, Fig. 5) as starting condition. A scheme illustrating the approach is given in Fig. 10, showing a simplified methane concentration profile of the water column and the mixing depth for August and November. The amount of methane remaining in the upper water column $V_{\text {rem }}$ is estimated based on sea surface methane concentrations in August and November assuming a homogeneous upper water column. $V_{\text {mix }}$ illustrates the amount of methane, which is mixed into the upper water column during the period August-November. Based on methane profile TF0113 and the model-derived mixing depth (see Sect. 2), $V_{\text {mix }}$ is approximated to be $203 \mu \mathrm{mol}$ and can be compared to the flux of $303 \mu \mathrm{mol}$ during the period August-November. The rough mass balance shows that the deepening of the mixing depth causes significant entrainment of methane into the upper water column and accounts for elevated methane saturation values during the period August-September as described in Sect. 3.4. A model-based estimation of sea-air exchange of methane as described in Bange (2004) was not attempted at this point due to the lack of available time series of water column methane concentration profiles of the Baltic Sea in the period of August to November 2010.

\section{Conclusions}

The first year of successful, continuous, and autonomous measurements of methane in the surface water of the Baltic Sea shows large regional and seasonal variations, influenced by a series of parameters. Processes controlling methane distributions in the surface water were identified on various temporal and spatial scales. In the area around the island of Gotland several upwelling events could be observed, elevating the local methane concentration in the surface water. Elevated methane concentrations in the surface water and water column of the Arkona Basin in February 2010 with up to $832 \%$ oversaturation could be related to a longer period of strong winds, resulting in a potential pressureinduced gas release from the underlaying methane bearing upper sediments. Upwelling, seepage or wind events develop on a rather short temporal and spatial scale; yet such events influence local methane distributions significantly. Temporal stratification and low mixing depths of the water column of the Baltic Sea occur on a longer time scale and inhibit methane transport from methane-enriched deeper water layers to the sea surface during summer. Thus, especially in deeper regions like Bornholm Basin and Gulf of Finland a methane reservoir is formed during the summer period, which is partly mixed to the surface from the beginning of autumn, leading to elevated methane concentrations for several months. Stratification in shallower regions like the Mecklenburg Bight is less dominant and no methane reservoir in deeper water persisting of longer periods of time can establish. We suggest that these regions are rather influenced by microbial methanogenesis in the sediment and emission of methane into the water column, short-time wind events and reduced solubility of methane by higher water temperatures during summer.

The Baltic Sea is a source of atmospheric methane with high emission values during the winter season $\left(0.015-1.145 \mathrm{nmolm}^{-2} \mathrm{~s}^{-1}\right)$ and low emissions during the spring and summer seasons $\left(0.008-0.162 \mathrm{nmol} \mathrm{m}^{-2} \mathrm{~s}^{-1}\right)$. Parameters controlling the methane fluxes alternate during the seasons depending on the region. Methane fluxes in shallow regions like the Mecklenburg Bight (0.057$0.225 \mathrm{nmol} \mathrm{m}^{-2} \mathrm{~s}^{-1}$ ) are higher compared to deeper regions like the Gotland Basin $\left(0.008-0.049 \mathrm{nmolm}^{-2} \mathrm{~s}^{-1}\right)$ and show significant changes during the seasons in connection with temperature driven methane solubility changes and methanogenesis in the sediment. Methane fluxes in areas with a permanent stratification like the Gotland Basin were found to be less variable during the year and mostly 
influenced by temperature-induced solubility and annual development of the mixed layer. Highest methane fluxes were derived for the Gulf of Finland in February 2010 with $1.145 \mathrm{nmol} \mathrm{m}^{-2} \mathrm{~s}^{-1}$. Here the influence of changing ice coverage needs to be investigated in more detail in the future.

The general seasonal trend of the surface water methane distribution in the Baltic Sea presented in this study could be confirmed by iterant patterns recorded in 2011. Interannual changes will be presented elsewhere once more data become available.

Acknowledgement. The research leading to these results has received funding from the European Community's Seventh Framework Programme (FP7/2007-2013) under grant agreement Nr. 217246 made with the joint Baltic Sea research and development program BONUS. The Swedish Meteorological and Hydrological Institute (SMHI) is acknowledged for providing data on river runoff to the Baltic Sea and sea level records at Kungsvik. Provision of COSMO/EU data for the Baltic Sea region by German Weather Service is appreciated. The National Oceanic and Atmospheric Administration (NOAA) is acknowledged for providing atmospheric methane data. We appreciate the cooperation with Seppo Kaitala (Algaline project leader) of the Finnish Environment Institute (SYKE) Helsinki and the ferry line company Finnlines. We gratefully acknowledge the technical support of Bernd Sadkowiak and Heiko Witt (IOW).

Edited by: S. W. A. Naqvi

\section{References}

Abril, G. and Iversen, N.: Methane dynamics in a shallow non-tidal estuary (Randers Fjord, Denmark), Mar. Ecol.-Prog. Ser., 230, 171-181, 2002.

Alenius, P., Myrberg, K., and Nekrasov, A.: The physical oceanography of the Gulf of Finland: a review, Boreal Environ. Res., 3, 97-125, 1998.

Bange, H. W., Bergmann, K., Hansen, H. P., Kock, A., Koppe, R., Malien, F., and Ostrau, C.: Dissolved methane during hypoxic events at the Boknis Eck time series station (Eckernförde Bay, SW Baltic Sea), Biogeosciences, 7, 1279-1284, doi:10.5194/bg7-1279-2010, 2010.

Bange, H. W.: Nitrous oxide and methane in European coastal waters, Estuar. Coast. Shelf S., 70, 361-374, 2006.

Bange, H. W.: Air-sea exchange of nitrous oxide and methane in the Arabian Sea: A simple model of the seasonal variability, Indian J. Mar. Sci., 33, 77-83, 2004.

Bange, H. W., Bartell, U. H., Rapsomanikis, S., and Andreae, M. O.: Methane in the Baltic and North Seas and a reassessment of the marine emissions of methane, Global Biogeochem. Cy., 8, 465480, 1994.

Bange, H. W., Dahlke, S., Ramesh, R., Meyer-Reil, L. A., Rapsomanikis, S., and Andreae, M. O.: Seasonal study of methane and nitrous oxide in the coastal waters of the Southern Baltic Sea, Estuar. Coast. Shelf S., 47, 807-817, 1998.
Bates, T. S., Kelly, K. C., Johnson, J. E., and Gammon R. H.: A reevaluation of the open ocean source of methane to the atmosphere, J. Geophys. Res., 101, 6953-6961, 1996.

Berger, U. and Heyer, J.: Distribution and activity of methanotrophic bacteris in a brackish water ecosystem, Limnologica, 8, 141-144, 1990.

Beljaars, A. C. M.: The parameterization of surface fluxes in largescale models under free convection, Q. J. Roy. Meteor. Soc., 121, 255-270, 1994.

Boetius, A., Ravenschlag, K., Schubert, C. J., Rickert, D., Widdel, F., Gieseke, A., Amann, R., Jorgensen, B. B., Witte, U., and Pfannkuche, O.: A marine microbial consortium apparently mediating anaerobic oxidation of methane, Nature, 407, 623-626, 2000.

Bussmann, I. and Suess, E.: Groundwater seepage in Eckernförde Bay (Western Baltic Sea): effect on methane and salinity distribution of the water column, Cont. Shelf Res., 18, 1795-1806, 1998.

Butler, J., Elkins, L. W., Brunson, C. M., Thompson, T. M., and Hall, B. D.: Trace Gases in and over the west pacific and east indian oceans during the El Ninio southern oscillation event of 1987, J. Geophys. Res., 94, 865-877, 1989.

COSMO: Core documentation of the COSMO-model, available at: http://www.cosmo-model.org/content/model/documentation/ core/default.htm, last access: 17 December 2012.

Dando, P. R., Bussmann, I., Niven, S. J., O'Hara, S. C. M., Schmaljohann, R., and Taylor, L. J.: A methane seep area in the Skagerrak, the habitat of the pognophore Siboglinium poseidoni and the bivalve mollusc Thyasira sarsi, Mar. Ecol. Prog.-Ser. 107, 157-167, 1994.

DeAngelis, M. A. and Lee, C.: Methane production during zooplankton grazing on marine phytoplankton, Limnol. Oceanogr., 39, 1298-1308, 1994.

Dlugokencky, E. J., Lang, P. M., and Masarie, K. A.: Atmospheric Methane Dry Air Mole Fractions from the NOAA ESRL Carbon Cycle Cooperative Global Air Sampling Network, 1983-2010, Version: 2011-08-11, 2011.

Feistel, R., Nausch, G., and Wasmund, N.: State and Evolution of the Baltic Sea, 1952-2005: A Detailed 50-Year Survey of Meteorology and Climate, Physics, Chemistry Biology and Marine Environment, John Wiley and Sons, Inc., Hoboken, New Jersey, 2008.

Grasshoff, K., Kremling, K., and Ehrhardt, M.: Methods of seawater analysis, 3rd Edn., Verlag Chemie, Gulf Publishing Houston, 1999.

Griffies, S. M., Harrison, M. J., Pacanowski, R. C., and Rosati, A.: A technical guide to MOM4. GFDL Ocean Group Technical Report No. 5, Geophysical Fluid Dynamics Laboratory, Princeton, 342 pp., 2004.

Grunwald, M., Dellwig, O., Beck, M., Dippner, J. W., Freund, J. A., Kohlmeier, C., Schnetger, B., and Brumsack, H.-J.: Methane in the southern North Sea: sources, spatial distribution and budgets, Estuar. Coast. Shelf S., 81, 445-456, 2009.

Gülzow, W., Rehder, G., Schneider, B., Schneider v. Deimling, J., and Sadkowiak, B.: A new method for continuous measurement of methane and carbon dioxide in surface waters using off-axis integrated cavity output spectroscopy (ICOS): an example from the Baltic Sea, Limnol. Oceanogr-Meth., 9, 176-184, 2011. 
Heyer, J. and Berger, U.: Methane emission from the coastal area in the southern Baltic Sea, Estuar. Coast. Shelf S., 51, 13-30, 2000.

Heyer, J., Berger, U., and Suckow, R.: Methanogenesis in diffrent parts of a brackish water ecosystem, Limnologica, 20, 135-139, 1990.

Heyer, J., Berger, U., Kuzin, I. L., and Yakovlev, O. N.: Methane emissions from different ecosystem structures of the subarctic tundra in Western Siberia during midsummer and during the thawing period, Tellus B, 54, 231-249, 2002.

ICES (Oceanographic Database and Services): International Council for the Exploration of the Sea, http://ocean.ices.dk/helcom, last access: November 2011.

Jähne, B., Heinz, G., and Dietrich, W.: Measurement of the diffusion coefficients of sparingly soluble gases in water, J. Geophys. Res., 92, 10767-10776, 1987.

Janssen, F., Schrumm, C., and Backhaus, J. O.: A climatological dataset of temperature and salinity for the North Sea and the Baltic Sea, Dt. Hydrogr. Zs., Supplement 9, 245 pp., 1999.

Karl, D. M. and Tilbrook, B. D.: Production and transport of methane in oceanic particulate organic matter, Nature, 368, 732734, 1994.

Karl, D. M., Beversdorf, L., Björkman, K. M., Church, M. J., Martinez, A., and DeLong, E. F.: Aerobic production of methane in the sea, Nature Geosci., 1, 473-478, 2008.

Keir, R., Schmale, O., Seifert, R., and Sültenfuß, J.: Isotope fractionation and mixing in methane plumes from the logatchev hydrothermal field, Geochem. Geophys. Geosyst., 10, 1-19, doi:10.1029/2009GC002403, 2009.

Körtzinger, A., Thomas, H., Schneider, B., Gronau, N., Mintrop, L., and Duiker, J. C.: At-Sea intercomparison of two newly designed underway $\mathrm{pCO}_{2}$ system-encouraging results, Mar. Chem., 52, 133-145, 1996.

Laier, T. and Jensen, J.: Shallow gas depth-contour map of the Skagerrak-Western Baltic Sea region, Geo.-Mar. Lett., 27, 127141, 2007.

Large, W., McWilliams, J., and Doney, S.: Oceanic vertical mixing: a review and a model with a nonlocal boundary layer parameterization, Rev. Geophys., 32, 363-403, 1994.

Lass, H. U., Mohrholz, V., Nausch, G., and Siegel, H.: On phosphate pumping into the surface layer of the eastern Gotland Basin by upwelling, J. Marine Syst., 80, 71-89, 2010.

Leuenberger, D.: Statistical analysis of high-resolution COSMO Ensemble forecasts in view of Data Assimilation, $48 \mathrm{pp}$., Tech. Rep., edited by: Milelli, M., ARPA Piemonte Printed at Deutscher Wetterdienst, Offenbach, May, 2010.

Lehmann, A. and Myrberg, K.: Upwelling in the Baltic Sea - a review, J. Marine Syst., 74, S3-S12, 2008.

Lips, I., Lips, U., and Liblik, T.: Consequences of coastal upwelling events on physical and chemical patterns in the central Gulf of Finland (Baltic Sea), Cont. Shelf Res., 29, 1836-1847, 2009.

Liss, P. S. and Merlivat, L.: Air-Sea Exchange Rates: Indruduction and Synthesis, Springer, New York, 113-127, 1986.

Mathys, M., Thießen, O., Theilen, F., and Schmidt, M.: Seismic characterization of gas-rich near surface sediments in the Arkona Basin, Baltic Sea, Mar. Geophys. Res., 26, 207-224, 2005.

Mogollón, J. M., Dale, A. W., L'Heureux, I., and Regnier, P.: Impact of seasonal temperature and pressure changes on methane gas production, dissolution, and transport in unfractured sediments, J. Geophys. Res., 116, G03031, doi:10.5194/bg-9-1915-
2012, 2011.

Nightingale, P. D., Malin, G., Law, C. S., Watson, A. J., Liss, P. S., Liddicoat, M. I., Boutin, J., and Upstill-Goddard, R. C.: In situ evaluation of air-sea gas exchange parameterizations using novel conservative and volatile tracers, Global Biogeochem. Cy., 14, 373-87, 2000.

Pimenov, N., Ulyanova, M. O., Kanapatsky, T. A., Veslopolova, E. F., Sigalevich, P. A., and Sivkov, V. V.: Microbially mediated methane and sulfur cycling in pockmark sediments of the Gdansk Basin, Baltic Sea, Geo.-Mar. Lett., 30, 439-448, 2010.

Rehder, G., Collier, R. W., Heeschen, K., Kosro, P. M., Barth, J. and Suess E.: Enhanced marine $\mathrm{CH}_{4}$ emissions to the atmosphere off Oregon caused by coastal upwelling, Global Biochem. Cy., 16, 11 pp., 2002.

Reindl, A. and Bolałek, J.: Methane flux from sediment into nearbottom water in the coastal area of the Puck Bay (Southern Baltic), Oceanol. Hydrobiol. St., 41, 40-47, 2012.

Schmale, O., Schneider v. Deimling, J., Gülzow, W., Nausch, G., Waniek, J. J., and Rehder, G.: The distribution of methane in the water column of the Baltic Sea, Geophys. Res. Lett., 37, L12604, doi:10.1029/2010GL043115, 2010.

Schmale, O., Haeckel, M., and McGinnis, D. F.: Response of the Black Sea methane budget to massive short-term submarine inputs of methane, Biogeosciences, 8, 911-918, doi:10.5194/bg-8911-2011, 2011.

Schneider, B., Kaitala, S., and Maunula, P.: Identification and quantification of plankton bloom events in the Baltic Sea by continuous $p \mathrm{CO}(2)$ and chlorophyll- $a$ measurements on a cargo ship, J. Mar. Syst., 59, 238-248, 2006.

Schneider v. Deimling, J., Greinert, J., Chapman, N. R., Rabbel, W., and Linke, P.: Acoustic imaging of natural gas seepage in the North Sea: sensing bubbles under control of variable currents, Limnol. Oceanogr.-Meth., 8, 155-171, 2010.

Schneider v. Deimling, J., Rehder, G., Greinert, J., McGinnis, D., Boetius, A., and Linke, P.: Quantification of seep-related methane gas emissions at Tommeliten, North Sea., Cont. Shelf Res., 31, 867-878, doi:10.1016/j.csr.2011.02.012, 2011.

Schulz, J.-P. and Schättler, U.: Kurze Beschreibung des LokalModells LME und seiner Datenbanken auf dem Datenserver des DWD, Technical Report FE13, Deutscher Wetterdienst, Offenbach, 65 pp., 2005.

Seifert, T.: Comparison of weather model data with station measurements, Internal Report, Institute for Baltic Sea Research, Warnemünde, 33 pp., 2010.

Seifert, T., Tauber, F., and Kayser, B.: A high resolution spherical grid topography of the Baltic Sea-revised edition, Baltic Sea Science Congress, 25-29 November 2001, Stockholm, Sweden, Poster 147, available at: www.io-warnemuende.de/iowtopo(last access: December 2012), 2001.

Siegel, H., Gerth, M., Rudloff, R., and Tschersich, G.: Dynamical features in the western Baltic Sea investigated by NOAAAVHRR-Data, Deutsche Hydrographische Zeitschrift, 3, 191209, 1994.

Siegel, H., Seifert, T., Schernewski, G., Gerth, M., Reißmann, J., Ohde, T., and Podsetchine, V.: Discharge and transport processes along the German Baltic Sea, Coast. Ocean. Dynam., 55, 47-66, 2005. 
Smagorinski, J.: General circulation experiments with the primitive equations: I. The basic experiment, Mon. Weather Rev., 91, 99164, 1963.

Sweeney C., Gloor, E., Jacobson, A. R., Key, R. M., McKinley, G., Sarmiento, J. L., and Wanninkhof, R.: Constraining global air-sea gas exchange for $\mathrm{CO}_{2}$ with recent bomb 14C measurements, Global Biogeochem. Cy., 21, GB2015, doi:10.1029/2006GB002784, 2007.

Thießen, O., Schmidt, M., Theilen, F., Schmitt, M., and Klein, G.: Methane formation and distribution of acoustic turbidity in organic-rich surface sediments in the Arkona Basin, Baltic Sea, Cont. Shelf Res., 26, 2469-2483, 2006.

Thomas, H. and Schneider, B.: The seasonal cycle of carbon dioxide in Baltic Sea surface waters, J. Marine Syst., 22, 53-67, 1999.

Thomas, S.: Vergleich und Optimierung analytischer Methoden zur Bestimmung des, Methangehaltes in Seewasser, Diploma Thesis, University of Rostock, Institute for Chemistry Germany, 2011.

Umlauf, L., Arneborg, L., Hofmeister, R., and Burchard, H.: Entrainment in shallow rotating gravity currents: a modeling study, J. Phys. Oceanogr., 40, 1819-1834, 2010.
Vahtera, E., Laanemets, J., Pavelson, J., Huttunen, M., and Kononen, K.: Effect of upwelling on the pelagic environment and bloom-forming cyanobacteria in the western Gulf of Finland, Baltic Sea, J. Marine Syst., 58, 67-82, 2005.

Wanninkhof, R.: Relationship Between wind speed and gas exchange over the ocean, J. Geophys. Res., 97, 7373-7382, 1992.

Wanninkhof, R., Asher, W. E., Ho, D. T., Sweeney, C., and McGillis, W. R.: Advances in quantifying air-sea gas exchange and environmental forcing, Ann. Rev. Mar. Sci., 1, 213-244, 2009.

Weiss, A., Kuss, J., Peters, G., and Schneider, B.: Evaluating transfer velocity-wind speed relationship using a long-term series of direct eddy correlation $\mathrm{CO}_{2}$ flux measurements, J. Marine Syst., 66, 130-139, 2007.

Wever, T. F., Lühder, R., Vo, H., and Knispel, U.: Potential environmental control of free shallow gas in the seafloor of Eckernförde Bay, Germany, Mar. Geol., 225, 1-4, 2006.

Whiticar, M. J. and Faber, E.: Methane oxidation in sediment and water column environments - isotope evidence, Org. Geochem., 10, 759-768, 1986.

Wiesenburg, D. A. and Guinasso, N. L.: Equilibrium solubilities of methane, carbon monoxide, and hydrogen in water and sea water, J. Chem. Eng. Data, 24, 356-360, 1979. 